Chapter 2

\title{
Insulin/IGF-Signalling in Embryonic and Adult Neural Proliferation and Differentiation in the Mammalian Central Nervous System
}

\author{
Tanja Vogel \\ Additional information is available at the end of the chapter \\ http://dx.doi.org/10.5772/54946
}

\section{Introduction}

\subsection{General overview of insulin/IGF-signalling}

The IIS cascades are initiated by binding of Insulin or Insulin-like growth factors (IGF-1 and -2) to their receptors, the Insulin receptor (IR), and the two Insulin-like growth factor receptor 1 (IGF-1r) and 2 (IGF-2r) (Fig. 1). While high affinity binding occurs between the cognate ligand-receptor pairs, each ligand binds to the other receptors with lower affinity [2]. IR, IGF-1r and $-2 \mathrm{r}$ are dimers that occur as homo- but also as heterodimers, the latter of which are studied in various cancer cells [3]. Such hybrid receptors are also found in the central nervous system, however a clear function for them has not emerged as yet [4] although activation of different signalling cascades followed by a different biological effect is a likely scenario [2]. IR, IGF-1r and $-2 \mathrm{r}$ are tyrosine receptor kinases that phosphorylate themself as well as downstream adaptor proteins like the insulin receptor substrate proteins (IRS-1-4) [5]. Through phosphorylation, IRS proteins bind to SRC-homology-2 (SH-2) domain-containing proteins like SRC, SRC homology2-B (SH2-B), protein phosphatases like Tyrosine-protein phosphatase nonreceptor type 1 (PTPN1), or the p85 subunit of phosphatidyl inositol 3-kinase (PI3K).

Two major signalling pathways are activated through IIS: the PI3K- and/or the RAS/Mitogenactivated protein kinase- (MAPK) pathways that are implicated in the regulation of a plethora of different cellular processes.

PI3K belongs to a family of lipid kinases that are grouped into three classes. Class IA PI3K are heterodimers of a p110 catalytic and a p85 or p55 regulatory subunit [6]. Binding of PI3K is followed by activation of the p110 catalytic subunit of the kinase, which catalyses the increase 
of phosphatidylinositol-3,4,5-triphosphate (PtdIns $\{3,4,5\} \mathrm{P} 3$ ) lipids. PtdIns $\{3,4,5\} \mathrm{P} 3$ induce phosphorylation of phosphoinositide-dependent protein kinase 1 (PDK-1), and the AGC kinase AKT. In mammals, AKT has three different isoforms, AKT-1,-2, and -3. Each of them has two critical sites in their activation domain, Thr308 and Ser473 that need to be phosphorylated both to achieve full kinase activation. Inactive AKT is localised in the cytosol, but it is recruited to the plasma membrane together with PDK-1 through association with phosphatidylinositol-4,5- diphosphosphate (PtdIns $\{4,5\} \mathrm{P} 2$ ) and PtdIns $\{3,4,5\} \mathrm{P} 3$. As a result, PDK-1 and AKT colocalise at the plasma membrane, which allows PDK-1 to induce phosphorylation of AKT at Thr308. AKT phosphorylation at Ser473 occurs by integrin-linked kinase (ILK) as well as mTORC-2 that are therefore PDK-2s for AKT [7]. Substrates of AKT are numerous, including pro-apoptotic proteins like BAD or anti-apoptotic proteins like BCL-2, NF- $\kappa$, and MCL-1, Forkheadbox transcription factors of the FOXO family as well as GSK-3 $\beta$. AKT also phosphorylates and inhibits the dimer tuberous sclerosis complex-1/-2 (TSC-1/TSC-2), which acts as inhibitory GTPase-activating protein for RHEB. The GTPase RHEB can activate mTORC-1, which has several substrates like p70 ribosomal protein S6 kinase (p70S6K), the translation initiation regulator $4 \mathrm{E}$ binding protein (4E-BP), and the proline-rich AKT substrate PRAS40. Through this signalling cascade, IIS activates mTORC-1 to promote cellular growth, translation, transcription, and autophagy. mTORC-1 activation initiates a negative feed back loop through active p70S6K that phosphorylates and inhibits IRS, thereby preventing activation of PI3K in response to IIS. As indicated above, mTORC-2 also influences upstream IIS by phosphorylating AKT as PDK-2 and is involved in spatial growth by regulating the actin cytoskeleton. However, little is known about mTORC-2 activation through IIS. Recent data suggest that mTORC-2 activation through IIS relies on a putative PI3K that is insensitive to the negative feed back loop that controls activation of mTORC-1 [8].

IIS triggering the RAS/MAPK pathways can lead to activation of a subset of three downstream kinases, ERK, JNK, and p38 [9] (Fig. 2). Activation of ERK is dependent on the RAS/MAPK pathway, in which IIS results in phosphorylated IRS or SHC that recruit growth factor receptorbound protein 2 (GRB-2). GRB-2 associates with the protein son of sevenless (SOS), which is a guanine nucleotide exchange factor. SOS acts by binding RAS-GTPase and forcing it to release bound GDP and to bind GTP instead, which results in an activated state. Activated RAS phosphorylates RAF, which in turn phosphorylates MEK that is responsible to activate the MAPK ERK-1/-2. Jun aminoterminal kinases (JNK-1/-2) are further members of the MAPK pathway that are as well activated through IIS. JNK activation is dependent on PI3K, whose catalytic subunit does not bind to p85 but to the small RHO-family GTPase CDC42 [10]. This complex activates MKK-4 (or MAP2K-4 (mitogen-activated protein kinase kinase 4), which finally phosphorylates JNK-1/-2. The mechanism of p38 activation via IIS is so far unclear [9].

PI3K- and RAS/MAPK-pathways also converge on some downstream molecules like FOXO proteins. Phosphorylation of FOXO through AKT leads to nuclear exclusion and interference with target gene expression. Several other sites are phosphorylated through ERK and p38 MAPK. Interference with these posttranslational modifications leads to decreased promoter binding together with ETS-1 transcription factor (TF) [11]. 


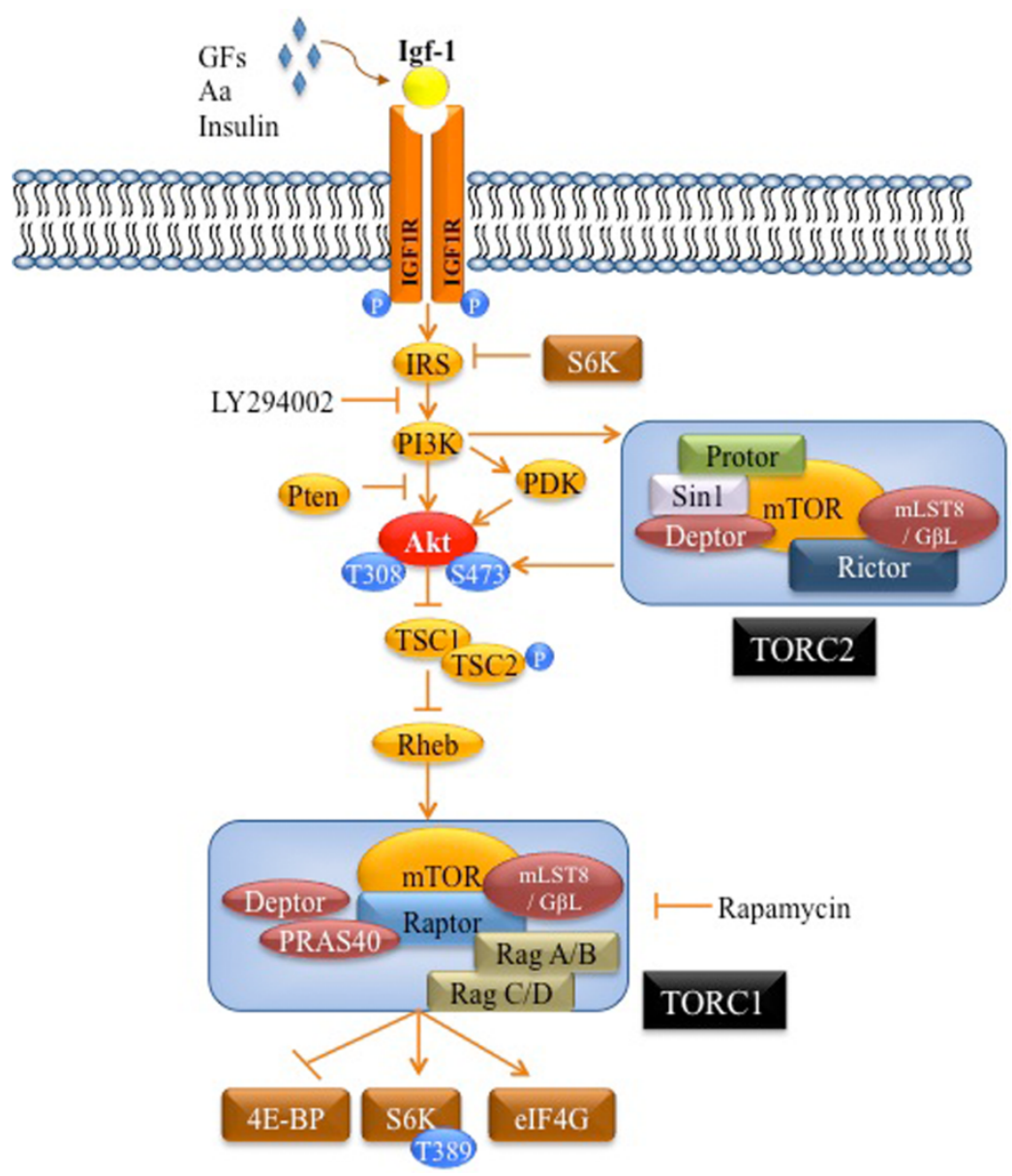

Figure 1. General overview of PI3K-dependent and mTor-driven IIS cascade and points of interference of serveral inhibitors commony used to study downstream IIS.

\section{Insulin/IGF-expression in the central nervous system}

Insulin, Igf- 1 and -2 as well as the three corresponding receptors are widely expressed in the developing and mature central nervous system (CNS) (for a recent review refer to [1]). Expression of Insulin and Igfs is in part under the control of Growth hormone (GH), but action of several tissue- and developmental-specific transcription factors are also involved in Insulin/ Igf expression as is the nutritional status (our own unpublished observations and [12-14]). Coordination and regulation of the biological activity of Igf- 1 and -2 , but not Insulin, is not only achieved by transcriptional or translational control but also through a set of proteins that have the ability to bind these ligands, namely the Igf-binding proteins (Igfbp). Upto date there 


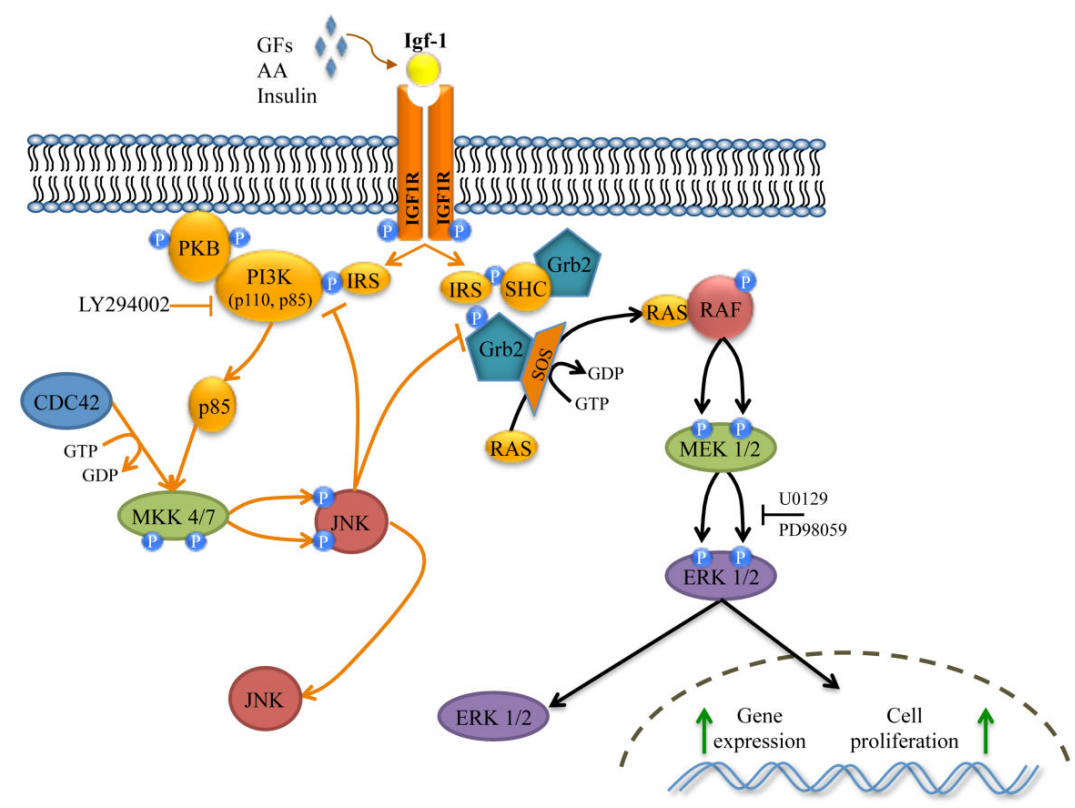

Figure 2. General overview of IIS activating ERK in RAS/MAPK-dependent and JNK in CDC42-dependent manner.

are several Igf- 1 and -2 binding proteins as well as Igfbp-related (or -like) proteins that bind to the ligands with varying affinities. Igfbps serve different functions, such as stabilisation and regulation of the concentration of diffusible Igfs, as well as facilitating receptor binding and modulation of Igf-bioavailability in the extracellular space [12]. Altogether, the various subtypes of Igfbps bind $99 \%$ of circulating Igf- 1 and -2 . Within this fraction, $75 \%$ are bound to Igfbp-3. Only $1 \%$ of Igf-1 and -2 is freely available in the extracellular space [15].

Igf- 1 and -2 as well as the Igfbps are widely expressed in the brain $[16,17]$. Their expression patterns have been described in multiple studies, mainly based on mRNA-detection methods (summarised in [12]). Accordingly, Igf-1 is strongly expressed in the spinal cord, midbrain, cerebral cortex, hippocampus and olfactory bulb $(\mathrm{OB})$ during development. Igf- 1 transcription decreases postnatally as cell maturation advances to reach low levels in the adult central nervous system. In the OB, Igf- 1 expression persists at high levels in cells that are constantly renewed even in the adult organism [18]. Igf-2 is also expressed in various brain regions and also declines over development. However, it is considered to be the most abundantly expressed Igf in the adult brain.

Igfbp-1 seems generally not to be present in sufficient amounts for detection in the central nervous system $[1,19]$. Expression of Igfbp- 2 is found over all gross neuroanatomical structures of the rat brain, increasing from E15 until adulthood [20]. In preneurogenic stages (E10], rat Igfbp-2 is strongly expressed in neuroectodermal structures of the neural tube and the neuroepithelium [21]. In the postnatal brain it is mainly confined to astroglia as well as to the 
choroid plexus and leptomeninges [22]. Accordingly, IGFBP-2 is found closely associated with human astroglial tumors. In this research field, it serves not only as a staging marker for glioblastoma but is exploited for therapeutic intervention [23]. IGFBP-2 as well as bound IGF-2 are overexpressed in high-grade astrocytomas. MMP-9-mediated proteolysis of IGFBP-2 leads to increased IGF-2 levels in these tumours. This accounts for increased aggressiveness of the tumours through growth- and motility-promoting effects [24]. Expression of Igfbp-3 in the brain is apparently not studied in great detail. However, Igfbp-3 expression increases after brain insults and it has been shown to be upregulated in Alzheimer's disease brains [25]. Igfbp-3 interacts with retinoic acid and might therefore also be implicated in cell differentiation [26]. Igfbp-4 expression is also detected in most brain regions with declining levels over development [20], being highly expressed in the hippocampus and cerebral cortex in adult stages [27]. A function apart from regulation of Igf action has not been described yet. However, Igfbp-4 expression is decreased in the cerebral cortex, hippocampus and the cerebellum in an in vivo model for amyotrophic lateral sclerosis (ALS) [28]. Igfbp-5 is expressed mainly within thalamic nuclei, leptomeninges and the perivascular sheaths in adult rats [27]. Igfbp-6 seems to be expressed in differentiated but not in proliferating cells. Embryonic expression of Igfbp-6 in the CNS seems restricted to the trigeminal ganglia. Igfpb-6 transcription increases postnatally after approx. 21 days in the forebrain and cerebellum, primarily in GABAergic interneurons. Higher levels are found in the hindbrain, spinal cord and dorsal root ganglia [29]. According to this strong association of Igfbp- 6 expression with the cerebellar sensorimotor system, overexpression of Igfbp-6 results in a reduced size of the cerebellum [30]. Igfbp-7 is produced in the adult hippocampus, e.g. in the dentate gyrus (DG) [31]. In the postnatal hippocampus, all components of the extracellular Insulin/Igf-signalling molecules were detected apart from Igfbp-1. Variable amounts of individual components were detectable over two developmental time points studied, as well as in different cellular sources, which comprise neurons as well as glial and endothelial cells, albeit Igf-familiy member expression in the latter two cell types were not studied in comprehensive detail.

In rodents, the Insulin-receptor (Ir) is expressed in the olfactory bulb (OB), cerebral cortex, hippocampus, hypothalamus, pituitary, cerebellum, and the choroid plexus [32]. Expression is high in early stages of development and declines in the adult, and is also more enriched in neurons compared to glia. Within mature neurons, enrichment is observed within the postsynaptic density [4,33]. Accordingly, Ir-signalling including downstream mediators like Ras/MAPK and PI3K/Akt/mTor are implicated in synaptic connectivity and dendritic structure [4]. Igf-1r has a similar expression pattern with high expression in the developing cerebellum, midbrain, OB, and hindbrain [12]. However, although expression of Ir and Igf- $1 \mathrm{r}$ is observed in hippocampus, there are local differences in their distriubtion: Ir is enriched in the CA1 region and Igf- $1 \mathrm{r}$ is more prominent in the CA3 region. Levels of expression of the Igf- $1 \mathrm{r}$ are higher during development and decline to adult levels shortly after birth in the brain parenchyma, while it stays relatively high in the choroid plexus, meninges and vascular sheaths.

Igf-2 receptor (Igf-2r) is also known as the mannose-6-phosphate (M6P) receptor, which has a role in lysosomal enzyme trafficking. Accordingly, the main function described so far is to internalise the Igf-2 ligand through endocytosis and to mediate degradation of Igf-2. However, 
recent studies reveal that Igf- $2 \mathrm{r}$ is also implicated in specific signal transduction, e.g. in the context of memory enhancement or fear extinction [13,31]. Igf-2r is also expressed in all major neuroanatomical structures, with high expressions in the hippocampus, $\mathrm{OB}$, retina, pituitary, brain stem, and spinal chord. Further it is detected in the choroid plexus, ependymal as well as endothelial cells [12].

Detailed analyses of expression of the upstream Igf-signalling members has been reported for the mouse late embryonic and postnatal cerebellum [34]. Igf-1r is ubiquitously expressed, whereas Igf- 1 is detected in a subset of Purkinje cells (PC) at E17.5 and in postnatal stages. Igf-2 is confined to the meninges and blood vessels. Both ligands are not detectable in dividing cerebellar granule precursor cells (CGP). Igfbp- 1 is not detected, but Igfbp- 2 is expressed wide spread in the meninges, PC, internal as well as external granule layer, and choroid plexus. Igfbp- 3 is restricted to PC, Igfbp- 4 to meninges and choroid plexus, and Igfbp-5 to Calbindinnegative cells of the PC layer. Igfbp-6 is only detected in later stages in a subset of PC.

According to the widespread expression of members of the upstream IIS, their developmental dynamics and cell type specificity, it is conceivable that this signalling pathway exerts important function for development, maintenance as well as function of the various parts of the central nervous system. Some of these functions that are mainly attributable to neuronal development and fate decision will be highlighted in the following sections.

\section{Biological effects associated with Insulin/IGF-signalling in neural development}

\subsection{Insulin/IGF-signalling in ESC}

Insulin and IGF are important factors to keep human ESCs in a proliferative state and to promote self-renewal, where upon IGF-1R has been identified as essential component [35]. Blocking of IGF-signalling results in differentiation, but it is unclear whether a certain cell fate is favoured under such condition. Downstream signalling of Insulin and IGF has also been studied in this context and revealed that blocking of this pathway at various points induced differentiation. In this study, blocking is achieved on the level of PI3K through LY294002, of AKT-1, and of mTOR-1 through Rapamycin. Treatment of human ESC with LY294002 results in loss of phosphorylation of the downstream molecules AKT, p70S6K, S6 as well as GSK-3 $\beta$ [35-38].

Together with stromal cell-derived factor 1 (SDF-1/CXCL-12), pleiotrophin (PTN), and ephrinB1 (EFNB1) IGF-2 induces differentiation of human ESC into TH-positive dopaminergic neurons [39].

Interestingly, retinol/vitamin A also induces Nanog transcription and the signal is transduced over the IGF-1R, IRS-1, AKT and both mTOR complexes, mTORC-1 and mTORC-2 [40]. Expression of Nanog is a hallmark of proliferating, pluripotent stem cells. However, Insulin has differentiating capacity into the neuroectodermal lineage when human ESCs are cocul- 
tured with endodermal derived cells. This effect is dependent on PI3K/AKT signalling [41]. Together, these results reflect context-dependent IIS, and possibly cross-talk with other signalling pathways activated e.g. in vivo through development or in vitro through cocultures.

\subsection{Insulin/IGF effects in embryonic neural precursors}

The Insulin-receptor (Ir) is expressed in distinct regions of the CNS, including the olfactory bulb (OB), hypothalamus and the pituitary. Accordingly, a Nestin-cre mediated conditional, CNS-specific knock-out of the Ir early during development results in increased Luteinising hormone (LH) release from the hypothalamic-pituitary axis that leads to a deregulation of energy homeostasis and endocrinology of the reproductive system [42].

Neurospheres generated from embryonic striatal precursors in the presence of Egf respond to Igf- 1 treatment with increased neuronal differentiation, presumably over an Igf- $1 \mathrm{r}$ dependent signalling cascade. However, this has not been addressed comprehensively through receptor inhibition but was deduced from lower differentiation upon Igf-2 and Insulin stimuli $[16,17,43]$. Igf- 1 treatment in this setting is not accompanied by increased cell proliferation, but cotreatment with Insulin increases the fraction of dividing cells. It might be that this effect is specific to this combined treatment.

In the cerebral cortex, increased Igf-1 expression after Growth hormone (GH) treatment of rat embryonal neural precursors is involved in increased proliferation of early (E14) and late (E17) progenitors and is accompanied by increased neuronal differentiation at both time points. In addition to neuronal differentiation, astrogenesis is also increased but only when late progenitors are exposed to GH. This effect is also blocked in the presence of an Igf-1-blocking antibody and thus illustrates that IIS is transducing GH-induced effects [42,44].

Increased proliferation of E14 rat cortical progenitor upon Igf-1 is observed in vitro after treatment of cultured cells, and in vivo after intrauterine Igf-1 injection [45].

Igf- 1 function in the brain is highly context-dependent and cell-type specific. This interpretation is corroborated by the finding that Igf-1 treatment of E19 rat embryonal hippocampal progenitors does influence survival of these cells [46].

In another setting, Igf-1 treatment evokes cell survival of mouse E10 neuroepithelial cells [47] and it is mitogenic for sympathetic neuroblasts [48], showing that progenitor subtypes respond differently to IIS. It is so far ill defined what kind of signalling events, including cross-talks to other pathways, are associated with this differential outcome of Igf- 1 stimulation. Interaction with Egf- as well as Fgf-2-signalling and Igf-1 has been studied in striatal-derived neural progenitor cells (NPCs). In this setting, highest numbers of formed spheres are obtained in the presence of Igf- 1 and Egf or Igf-1 and Fgf-2. Sphere formation in this context is highly dependent on presence of Igf-1, since no spheres were observed in the absence of IIS [49]. These data show that Igf- 1 is also affecting NPC proliferation in cooperation with other signalling molecules, emphasising the pleiotrophic nature of IIS.

Igf-1-signalling seems to increase the effects of Fgf-2 on NPC proliferation as has been shown in various stem cell populations, like rat adult SVZ neurospheres [50], neurospheres from 
mouse E13.5 forebrains [51], mouse embryonic OBSC [52], and mouse embryonic striatal NPC [49]. Although not shown in all stem cells investigated so far, it is likely that in one scenario Igf-1 promotes survival and proliferating competence of stem cells but that other mitogens such as Erk-activators are needed to increase proliferation. However, other stem cell populations might proliferate upon IIS without further mitogenic instructions as has been observed by Fgf-2-independent Igf-1-mediated proliferation in rat embryonic NPCs from the cerebral cortex and the hippocampus $[45,46]$.

NPCs from neonatal rat forebrain undergo neuronal differentiation upon Insulin-treatment [53]. The content of GFAP-positive cells in the neurosphere-based assay is unchanged, thus suggesting a preference for neuronal differentiation in this cellular model.

Embryonal stem cells from the olfactory bulb (OBSC) are strongly dependent on IIS as shown in vitro as well as in vivo. Igf-1 increases OBSC proliferation as well as differentiation without strong lineage restriction, thus affecting neuronal as well as glial differentiation [54]. OBSC proliferation however does not depend strictly on Igf-1, Insulin or pro-Insulin, they rather potentiate the proliferating effect of Fgf-2 and Egf [52]. This study also showed that Igf-1 induces differentiation into the neuronal and astroglial lineages, but oligodendrocyte differentiation clearly depends on presence of other growth factors.

Several data support the finding that Igf- 1 and -2 increase cerebellar granule cell precursor (CGP) proliferation as well as survival of the same [34,55]. Different effects were linked to different concentrations of the cytokine, where lower concentrations favoured survival and higher proliferation [56]. IIS is supporting Sonic hedgehog (Shh) action that is a potent mitogen for CGPs. Blocking of signal transduction through the Igf-1r diminishes Shh-mediated cell proliferation, as well as endogenous supply of Igfbp-5. However, other Igfbps do not interfere with Shh-mediated proliferation, but decrease Igf-1-dependent cell division [34].

Igf-2 treatment of CGP also results in proliferation. However it is unclear whether this occurs over the Igf- $1 \mathrm{r}$ or $2 \mathrm{r}$ [57] but it indicates also important function for Igf-2 in the context of development of the central nervous system.

Igf-1 prevents cell death in primary rat embryonic hippocampal cultures after exposure to glucocorticoids. While increased levels of corticosterone reduce Akt-phosphorylation and lead to cell death, Igf-1 rescues cells from dying by increasing pAkt-levels in a PI3K-dependent manner [58]. The same effect is observed by applying Insulin instead of Igf-1 [59].

Signalling of Insulin/Igf affects NPC proliferation, survival as well as differentiation in vitro and this finding is corroborated in vivo by studies of knock-out and transgenic mouse models. Transgene-mediated overexpression of Igf-1, driven by the Nestin-promoter, supports in vitro finding that Igf-1 influences NPC proliferation as well as neuronal differentiation during development. Cumulative BrdU-labelling shows that Igf-1 decreases the total length of the cell cycle through acceleration of the G1-phase. This higher proliferating activity is paired with a higher rate of cell-cycle re-entry. The overall increased number of progenitors provides a larger pool of NPCs for neuronal differentiation and thus increases numbers of neurons residing in the postnatal cortical plate of Igf-1-overexpressing mice [60]. In vivo, Igf-1 also exhibits survival function since apoptosis is reduced upon its overexpression $[61,62]$ which further contributes 
to increased numbers of neurons in the cortical plate. Igf-1 signalling does not affect all neuronal populations in a similar manner but shows regional differences. The neuronal composition of the motor cortex is more increased than the somatosensory cortex of Igf-1overexpressing mice, which is however also increased compared to wildtype animals. Neurons in the cortical plate are also differently affected. Layer 1 neurons comprise the most increased neuronal fraction in Igf-1-transgenic brains, layer 6 neurons show the smallest increase [63]. It is thus likely that NPC are more sensitive to IIS during early developmental events of the cerebral cortex in which neurogenesis of frontal precedes that of caudal regions and layer 1 is preceding generation of layer 6 .

In line with in vivo overexpression studies, complete loss of Igf-1 in mice leads to the opposite effect of decreased numbers of specific neuronal populations in the cerebral cortex, e.g. hippocampal granule cells and striatal parvalbumin-positive interneurons. Dopaminergic neurons of the midbrain, basal forebrain cholinergic neurons, as well as motoneurons in the spinal cord do not depend on Igf-1 presence [64]. Further analysis of this Igf-1-deficient mouse revealed Igf-1-dependence of axonal growth and myelination that are strongly impaired. Overall, Igf-1-deficient mice have a decreased number of myelinated axons. This observation goes in line with studies of human IGF-I overexpression driven by a mouse metallothionein promoter, that revealed increased myelin production by an unchanged number of oligodendrocytes in adult brains [65].

Overexpression of Igf- 1 driven by the Igf-2 promoter results in general brain overgrowth. The greatest effect is seen in the cerebellum, although Igf- 1 deletion does not lead to an observable phenotype in this part of the brain, maybe because of compensatory effects from Igf-2 [55,64].

Igf-1r-deficient mice show severe growth retardation and die perinatally. Nestin-cre-mediated conditional knockout of the Igf-1r also results in death shortly after birth but few animals survive up to adulthood [66]. Mice that are heterozygote for the conditional Igf-1r deletion also display severe growth retardation that was studied in detail in the hippocampus. In the postnatal hippocampus all different parts are affected by increased rates of apoptosis rather than by an impaired ability to proliferate through loss of the Igf-1r.

Mutations of the type 2 Igf receptor are lethal but are rescued from this perinatal lethality in Igf-2 and Igf-1r null backgrounds [67]. This observation is attributed to increased Igf-2 signalling due to lack of internalisation of Igf-2, which is thought to be a major function of the Igf-2r. Although general hyperplasia is observed including the brain, Igf-2r-signalling was not further investigated in the brain [67-69].

Deletion of Igf-2 in mice results in severe growth-deficiency, but it was reported that Igf-2deficient mice do not show striking morphological aberrations [70,71]. However, one source of Igf-2 during development is the choroid plexus, from which it is released into the cerebrospinal fluid (CSF), and CSF-derived Igf-2 is an important signal for cell proliferation of later embryonic precursors that have contact to the ventricular surface [72]. Progenitors of the SVZ, e.g. Tbr-2-expressing cells, do not have contact to the CSF and thus are not influenced by Igf-2signalling in their proliferation capacity. Increased proliferation of cortical progenitors is dependent on the apical (ventricular) localisation of the Igf- $1 \mathrm{r}$ that is mediated through the cell 
polarity protein Pals-1 (Protein Associated with Lin Seven 1) as part of the apical complex. Further support for an Igf-1r-mediated effect of Igf-2-signalling in this context comes from the finding that loss of Pten (Phosphatase and Tensin homolog) opposes the effect of Pals-1deficiency: Pten-deficient mice have hyperplasic cortices while Pals-1-deficiency results in cortical hypoplasia. The phenotypes are partially reverted through combination of both transgenes [72]. Further downstream signals apart from Igf-1r and PI3K are not analysed in this context.

The function of different Igfbps has been studied through transgenic mouse models. Thereby it turned out, that loss of function mutations do not result in gross morphological changes within the CNS. However, overexpression of Igfbps lead to phenotypes in the CNS, which are exploited to achieve better understanding of IIS within this organ. Overexpression of Igfbp-1 in transgenic mice using either a phosphogylcerate kinase [73] or a methallothionein [74] promoter results in similar phenotypes as observed in adult Igf-1-deficient mice: reduced brain sizes due to loss of mature neurons and decreased progenitor proliferation, impaired myelination as well as decreased activation of GFAP-expressing astrocytes in conditions of injury. However, Igfbp-1 is normally not expressed at detectable levels in the CNS and the observed findings are therefore attributed to the lack of Igf- 1 as consequence of increased presence of Igfbp-1. Most of the phenotypes observed in mice overexpressing Igfbps resemble those of loss of Igf-1-signalling, which is mainly characterised by reduced organ size. Whether these phenotypes are exclusively caused by impaired Igf-1-signalling or whether Igfbps have also distinct functions, is so far not resolved [75]. Generally, Igfbp-5 is considered to potentiate Igf-1-signalling, while Igfbp-2 mainly opposes Igf- 1 and Igf-2 action [55]. This finding indicates that some Igfbps might exert additional functions that might only be apparent in transgenic mice in which the ligands are mutated as well.

\subsection{Insulin/IGF effects in adult neural precursors}

Igf-1, though not produced in high amounts in adult rodent brains, is required for normal neuronal functions throughout life. As different source, peripheral Igf- 1 is transported to neuronal cells through an uptake from the blood stream (reviewed in [1]). Neural stem cells of the adult hippocampus respond to peripheral administered Igf- 1 with increased proliferation as well as neurogenesis but not with astrogenesis [76]. These data were also confirmed in vitro using neurospheres generated from the hippocampal dentate gyrus. In this setting, low doses of Igf-1 mediate, and high doses interfere with neuronal differentiation [77]. Igf-1mediated cell proliferation of adult neuronal progenitor from the hippocampal subgranular zone (SGZ) was also shown in a model of epilepsy [78] as well as in response to physical excercise [79].

Further in vivo evidence for importance of Igf-1-signalling in the adult hippocampus comes from a study of Igf-1-deficient rats. In this context Igf-1 supports survival of newly generated neurons and possibly the maturation of the neuronal phenotype. However, cell proliferation is not affected in this in vivo model [80]. Igf-1-instructed differentiation mainly into the oligodendroglial lineage has been shown in rat adult hippocampal NPC [81] (Fig. 3). In this study, withdrawal of proliferation-promoting Fgf-2 is essential to drive NPCs into differen- 


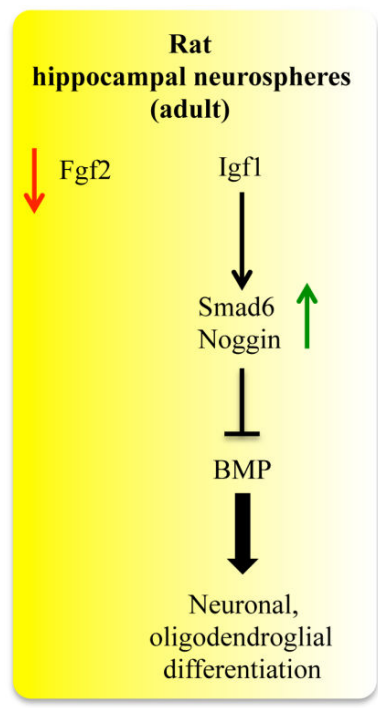

Figure 3. Igf-1 signalling in adult rat hippocampal neurospheres [81].

tiation upon Igf-1. IIS in this setting induces expression of Bmp-antagonists Noggin and Smad6, which are involved in the inhibition of an astrocytic cell fate and in favouring neuronal, but more efficiently oligodendroglial differentiation. Further, this study showed again that Igf-1 has a major impact on cell survival of adult NPCs.

Overexpression of Igf-1 through an Igf-2 promoter element results in increased numbers of neurons in the postnatal mouse hippocampal dentate gyrus. This increase in neurogenesis is transiently accompanied by increased numbers of synapses, which makes it possible that IIS also influences synaptogenesis [82].

Adult rat NPC derived from the subventricular zone proliferate stronger upon an Igf-1 stimulus. This effect is blocked by the presence of Igfbp-3 that also decreases phosphorylation of Akt [83]. Igf-1 signalling under Fgf-2-free conditions in adult subventricular stem cells is also linked to differentiation [84]. Adult mouse NPC are initially cultivated in the presence of Fgf-2. Subsequent withdrawal of Fgf-2 results in neuronal differentiation that is increased by complementation with Igf-1. Blocking of the Igf-1 signal with an antibody reverts the effect [85]. In this setting, the authors also explored the capacity of Igfbp-2 to influence the neurogenic potential of the NPC, since Igfbp-2 complexes with Igf-1 and proteoglycans like heparin in the rat OB [86]. Low doses of exogenous Igfbp-2 increase neuronal differentiation, while application of a blocking Igfbp-2 antibody interferes with this effect. These experiments indicate that Igfbp-2 does not act by sequestering Igf- 1 and by limiting its bioavailability, in which scenario Igfbp-2 would have an opposing effect to Igf-1. Instead, both molecules exert the same phenotypic differentiation and this indicates that Igfbp-2 function in this context is more likely a protection of Igf- 1 from degradation. It is conceivable that simultaneous interaction of Igfbp-2 
with proteoglycans decreases its affinity to Igf- 1 . The net outcome might be a locally increased amount of free Igf-1 that drives neuronal differentiation of NPC [85]. In another study, differentiation of SVZ NPC was deduced from reduced expression of the stem cell marker Nestin after Igf- 1 treatment, but it was not specified whether differentiation of a specific cell lineage was favoured [50].

Further studies in adult mice show that lack of Igf- 1 results in disturbed neuroblast exit from the subventricular zone and their subsequent migration to the olfactory bulb through the rostral migratory stream. This Igf-1 function is dependent on PI3-kinase activity and Disabled-1 (Dab-1) phosphorylation via Src-family kinase [87].

Igf-2 is not only provided from the CSF and important for early development of the brain. In addition, adult mouse hippocampal stem cells from the DG also produce Igf-2, and to a much lesser extend Igf- 2 is also detected in adult SVZ-derived stem cells $[19,88]$. Challenging Igf-2 expression through siRNA-mediated approaches as well as treatment of DG-derived NPCs reveals that Igf-2 also influences proliferation. However, SVZ-derived NPCs do not respond with changed proliferation upon Igf-2 knockdown [88]. Igf-2 but not Igf-1 is involved in neuronal survival of newly generated neurons in the adult DG in a model of fear extinction, that is strongly associated with neurogenesis in the hippocampus [31]. Neuronal survival and fear extinction depend on Igf-1r activity and are opposed by increased levels of Igfbp-7. However, Igf-1 does not exert any observable effect in this setting.

FoxO proteins are under the control of IIS and therefore a downstream read-out of this important signalling pathway. GFAP-cre was used to generate a triple allelic knockout of FoxO1, 3, and 4 in adult NPCs. The observed effect on cell proliferation is dependent on the age of the animal or passage of cells in culture. NPCs from young (P8) brains displayed hyperproliferation upon loss of FoxO-proteins and the same was observed for early passages of NPCs in culture. This initial hyperproliferation is followed by decreased doubling times and the depleted progenitor pool results in declining neuronal differentiation. FoxOs balance NPC proliferation and prevent premature loss of NPCs. Microarray studies revealed several cell-cycle regulating genes that are affected in their expression by the loss of FoxO. Furthermore, Aspm (asp (abnormal spindle)-like, microcephaly associated) and anatgonists of the Wnt-signalling cascade, Sfrp-1 (secreted frizzled-related protein) and -2, as well as Sost (sclerostin), are involved in the FoxO-dependent regulation. In this context FoxO might control Wnt-induced cell proliferation by expression of Wnt-antagonists [89].

\subsection{Insulin/IGF effects in mature neurons}

Igf-1 applied to postnatal cerebellar granule neurons (CGN) prevents cell death, thus establishing IIS as survival factor in mature neurons [90]. Another study described a link of Igf-1-signalling in mature neurons to survival of CGN as well as of cortical neurons. Here, Igf- 1 prevents apoptosis through activation of PI3K/Akt, but also through Igf-1r-dependend transactivation of unliganded Pac-1r (PACAP type 1 receptor) via Src-kinase activity [91] (Fig. 4). 


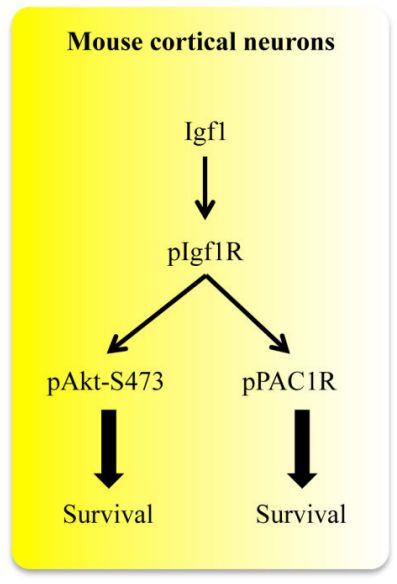

Figure 4. IIS mediated sur-vival of cortical neurons through activation of Akt and PAC-1r [91].

Data from adult Igf-1-deficient mice show however that cerebellar neurons are not affected by the loss of this trophic factor in vivo [64]. Contrasting this finding is data showing overexpression of human IGF-1 in mouse through a transgene driven by the mouse Igf-2 promoter [92] that results in cerebellar overgrowth through blockage of the ontogenetic cell death that normally takes place during early postnatal cerebellar development.

Blocking Igf-1 uptake through systemic application of an Igf-1 antibody not only reduces cell proliferation in the adult rat and mouse hippocampus, but is also implicated in synaptic remodelling and interferes with exercise-induced increase of dendritic spines [93]. IIS is also implicated in neuronal maturation and stimulates neurite outgrowth. In postnatal rat slice cultures of the somatosensory cortex, Igf-1-treatment leads to increased apical and basic dendritic branching of pyramidal neurons [94]. As such, Igf-1 is involved in forming mature neuronal networks and ensuring proper information processing. Further data show that Igf-1 mediates axonal growth by inducing plasmalemmal expansions by incorporation of vesicles in the growth cone [95]. This Igf-1-, but not Insulin-dependent effect is mediated by signalling via a growth-cone-specific Igf-1 receptor $(\beta g c)$, Irs-2, Shp-2, PI3K and Akt. This cascade might also influence dynamics of the cytoskeleton, namely microtubules and actin, both of which are required for axonal growth.

Igf-2 has recently been shown to control the number of synaptic connections and plasticity in mature neurons of the hippocampus $[13,14]$. Memory enhancement is specifically associated with Igf-2 function. In this context Igf- 2 is regulated by CCAAT enhancer binding protein $\beta$ $(\mathrm{C} / \mathrm{EBP})$ in adult rat hippocampus. $\mathrm{C} / \mathrm{EBP}$ is one of the transcription factors necessary for memory consolidation. In the study of Chen et al. rats are exposed to increased Igf-2 levels in the hippocampus during memory training which results in improved learning [13]. This effect is specific to Igf-2, since injection of Igf- 1 did not have any observable effect in this memory consolidation paradigm. 
Taken together, IIS has different effects in the developing and mature CNS that vary among the different cell types as summarised in Fig. 5. Differences might be mediated through specific downstream cascades or effector molecules present in only one specific cell or at a specific developmental time point. Another scenario is the cross-talk between IIS and other cytokines that are produced by the organism. Posttranslational modification of the receptors might be another general mechanism that specifies different biological responses to common signal inducers (ligand/receptor) and common intracellular signal transducers. The IGF-1r is sumoylated and modulated in its activity. Sehat et al. showed [96] this sumoylation of the IGF-1 receptor that leads to internalisation of the ligand bound protein complex, which is transduced to the nucleus and binds directly to genomic DNA. Since binding occurs predominantly in intergenic regions, the biological relevance for differential gene transcription has still to be shown. But nevertheless this reflects a possible mechanism through which specificity in activation of different target genes upon the same stimulus might be obtained in different cells or in the same cells at different developmental time points.

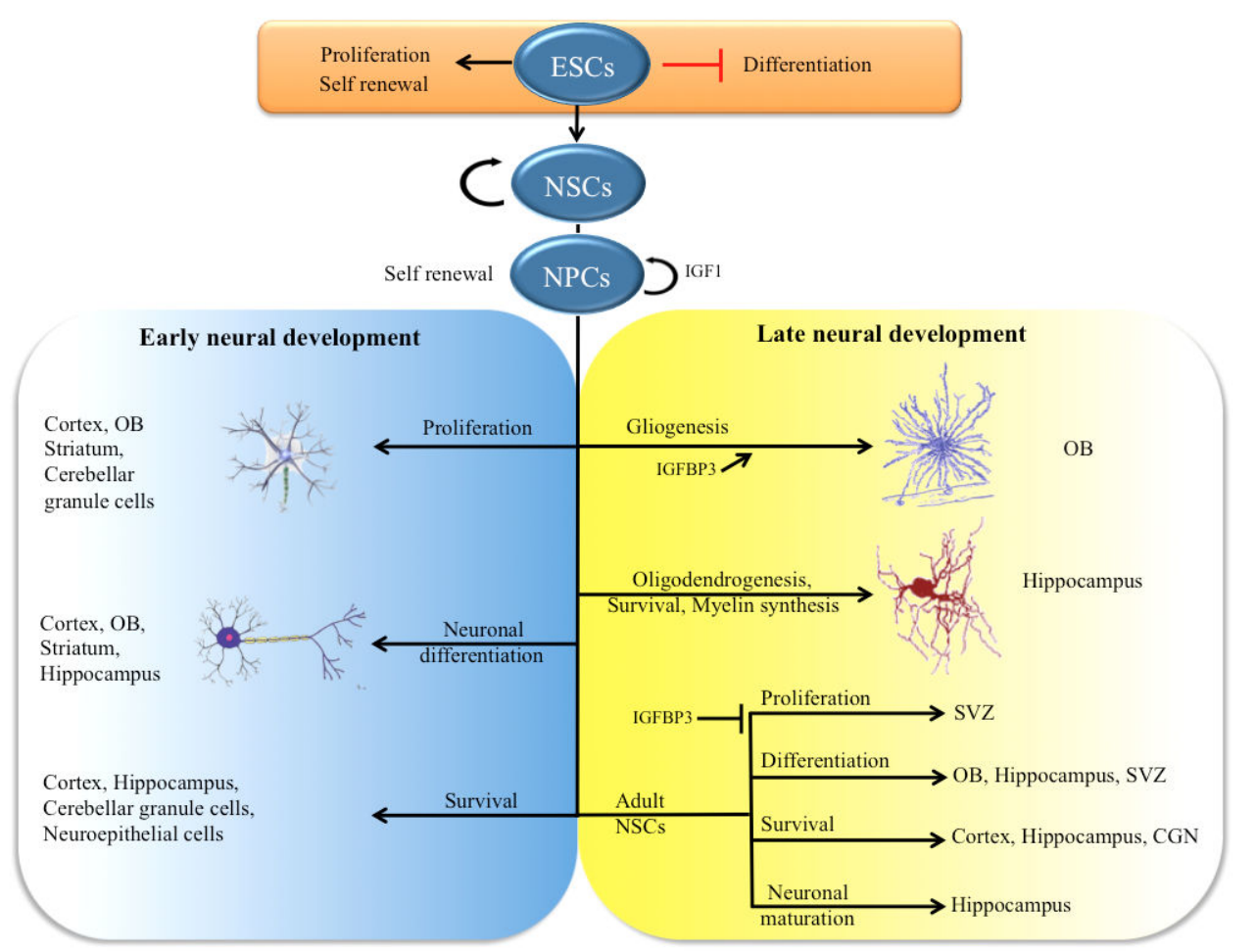

Figure 5. Differences in IIS function in different cell types of the CNS and in developmentThe Insulin-Igf Signalling (IIS) pathway has multiple effects on different cells of the CNS. The effects, beginning from cues for ESC proliferation and self-renewal, transcend to those of proliferation, self-renewal, differentiation and fate determination of NPCS. IIS contributes to either formation of neurons, or glia, oligodendrocytes and myelin. 


\section{Insulin/IGF-signalling networks}

\subsection{Signalling networks in neural progenitors and neurons}

Igf-1-dependent embryonal NPC proliferation in rat has been shown to be dependent on the PI3K/Akt pathway, but not on the MAPK/Erk branch of signalling. Chemical inhibitors of the latter, U0129 and PD98059, have no effect on NPC proliferation, while PI3K-inhibition through LY294002 interferes with Akt- and downstream Gsk-3 $\beta$-phosphorylation as well as proliferation. Phosphorylated and thus inactivated Gsk-3 $\beta$ leads to stabilisation of CycD1 (Cyclin D1). Together with increased expression of $\mathrm{CycD} 3$, and $\mathrm{CycE}$ as cell cycle promoters, decreased expression of inhibitory cell cycle proteins p27 and p57 is observed upon Igf-1-treatment and accounts for the mitogenic effect of Igf-1 [45] (Fig. 6).

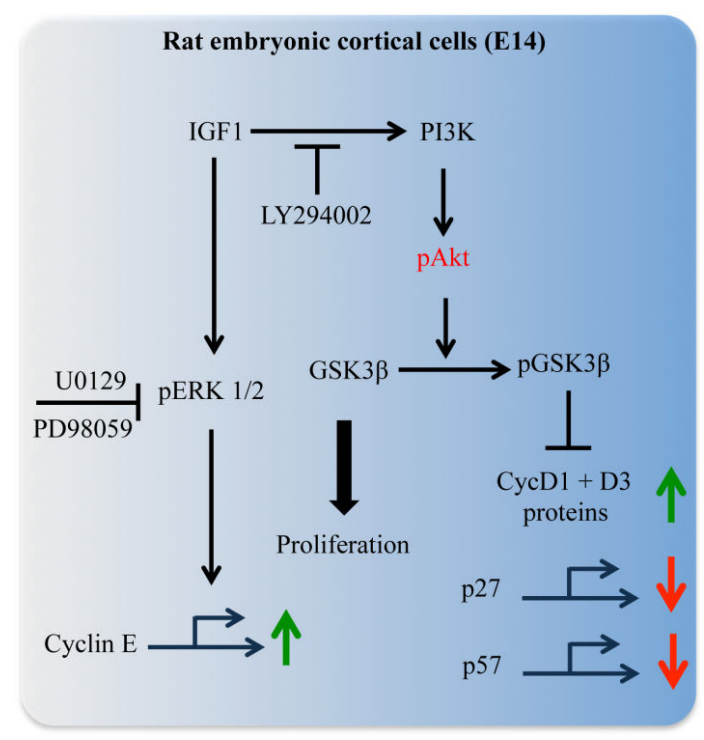

Figure 6. Igf-1-dependent embryonal NPC proliferation in rat [45].

Cortical progenitors isolated from mouse E13.5 brains were investigated with regard to increased Akt-1-signalling. Overexpression of Akt-1 results in increased proliferation as well as survival of progenitors in vivo and in vitro, consistant with effects of increased IIS. This Akt-1 function does not depend on its action upon p21, but at least in part of mTorc-1, because proliferation is partially hampered through Rapamycin. Survival is not affected through mTorc1 inhibition [97]. Differential downstream signalling of Akt in cortical progenitors is indicated by this study, which also reports that Rapamycin does only block proliferation in a subset of cells at E13.5, and progenitors of later developmental stages are also insensitive to Rapamycin with regard to proliferation (Fig. 7). 


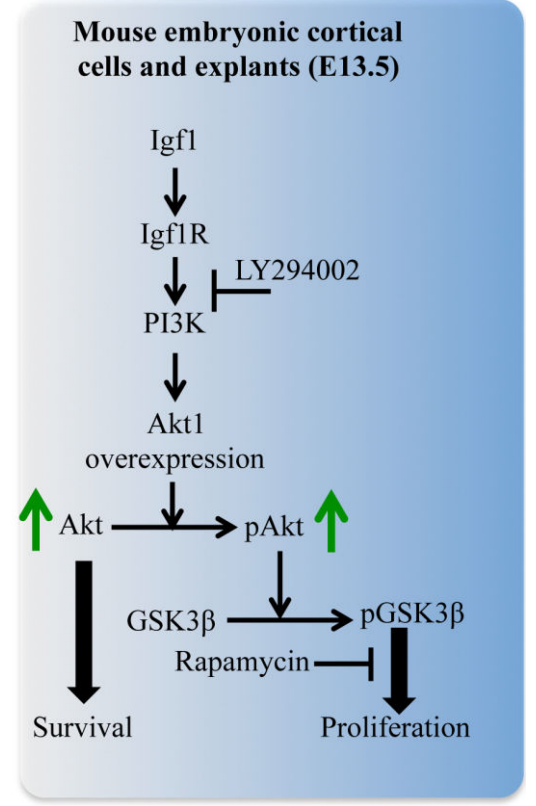

Figure 7. Survival and proliferation upon Igf-1 treat-ment in mouse E13.5 cortical cells [97].

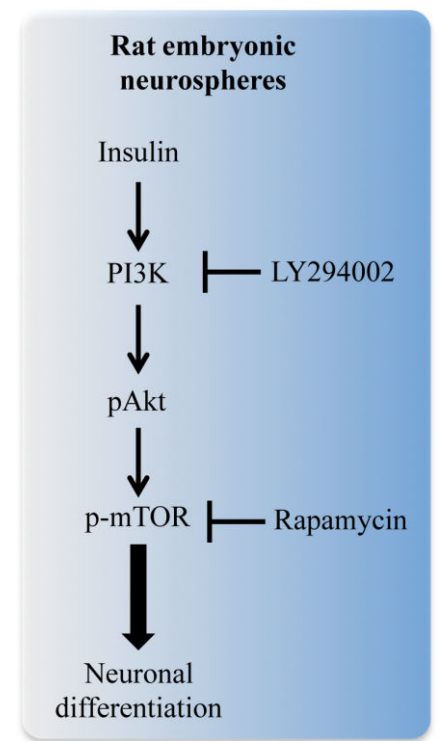

Figure 8. Insulin-dependent neuronal differentiation of embryonic neurosheres [50]. 
MTorc-1 inhibition through Rapamycin prevents neuronal differentiation of rat embryonic telencephalon-derived neurospheres that is observed in response to Insulin-signalling [53]. In this setting, Insulin-treatment results in phosporylation of mTorSer2448 and of pS670K, and the former is blocked through addition of Rapamycin, indicating that mTorc-1 is implicated in neuronal differentiation. Apoptosis is not observed under these conditions (Fig. 8).

MTor-1-dependent neuronal differentiation is also observed in P19 embryonic carcinoma cells that express Pax-6 as well as Hes- 5 upon retinoic acid treatment and initiation of neural differentiation. In this setting, Cdc42 is placed as upstream regulator of mTorc-1, and treatment with Rapamycin abolished Cdc42-mediated neural lineage specification as well as terminal neuronal differentiation [98].

MTorc-1 is also implicated in cell proliferation of rat adult hippocampal progenitors that heavily depend on PI3K-activated Akt-signalling. MTorc-1-dependence is obvious because presence of Rapamycin interfered with increased cell proliferation under Fgf-2-stimulation. Although Igf- 1 treatment of these cells did not result in increased proliferation, Igf- 1 increases cell division in the presence of Fgf-2 over the rate that is achieved through Fgf-2 alone [99]. Sustained activation of mTor-signalling in mice that are deficient for Tsc- 1 results in initially increased proliferation of NPC and premature depletion of the progenitor pool. Self-renewal of Tsc-1-deficient and thus mTor-activated NPC is also dramatically impaired. In addition to increased numbers of cells that differentiate into the neuronal lineage, sustained mTor activity interferes with terminal differentiation of neurons but seems to promote an increase in astrocytes [100]. Increased cell proliferation is also a hallmark of Tsc-2-deficient mouse NPC that are isolated from early (E10.5) developmental time points. This phenotype is also attributed to an activation of mTorc-1-signalling [101].

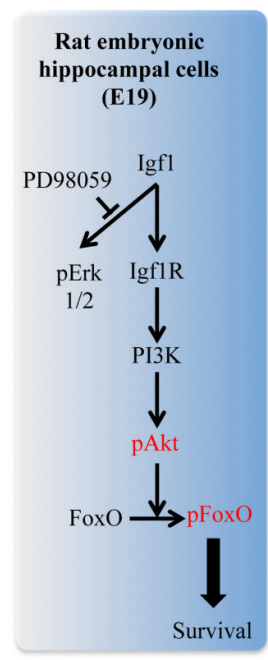

Figure 9. Igf-1-dependent survival of rat hip-pocampal precursors [46]. 
Igf-1-initiated survival of E19 rat embryonal hippocampal cells is dependent on PI3K-mediated Akt-phosphorylation and subsequent phosphorylation of FoxO3. Phosphorylation of FoxO3 is blocked by LY294002 and partially by Rapamycin, and results in increased survival of hippocampal progenitors. Blocking of MAPK/Erk pathway with PD98059 does not influence survival of these progenitors [46,102] (Fig. 9).

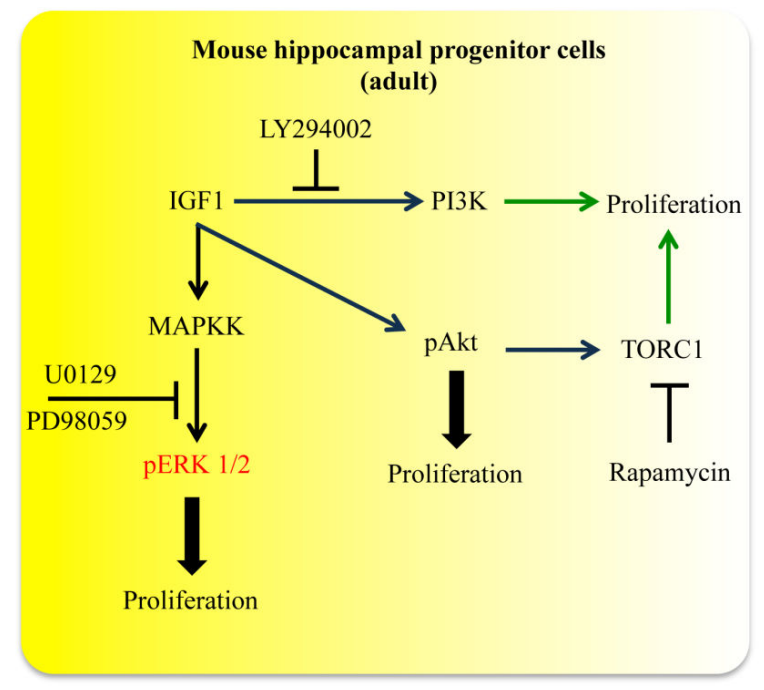

Figure 10. IIS in regulation of proliferation of adult hippocampal progenitors $[77,78]$.

Igf-1-mediated proliferation of neural progenitors of the adult DG is mainly but not exclusively mediated by MAPK/Erk-signalling, since inhibition of MAPKK/Mek-1/2 through a chemical inhibitor or dominant negative kinases interferes with cell division after Igf- 1 treatment. Blocking of PI3 kinase through LY294002 interferes with proliferation even without addition of Igf-1. However, blocking of the Akt-downstream signal through use of a dominant negative kinase also reduces Igf-1-induced mitosis. This finding makes it likely that LY294002-independent activation of Akt might be important for Igf-1-mediated proliferation. Rapamycin does not have significant effects in this setting, making it likely that mTor-complexes are not involved in Igf-1-mediated proliferation of adult hippocampal progenitors [77] (Fig. 10). Further evidence for the implication of Igf-1/MAPK/Erk- signalling in proliferation of adult hippocampal progenitors comes from the study of increased mitosis after a status epilepticus. Here, this lesion activates Igf-1-release from microglia. This increase in Igf-1 results in the activation of the MAPK/Erk-pathway and subsequent cell division. This response is blocked through inhibition of the Igf-1r as well as through U0129-mediated inhibition of the MAPKpathway [78].

It is interesting to point out that the same biological effect can be achieved through Igf- 1 by activating different pathways in different cells: IIS induces proliferation in embryonic rat 
cortical progenitors in an Erk-independent manner, while Igf-1 signalling induces proliferation of adult hippocampal progenitors via Erk-dependent cytoplasmic downstream signals. On the other hand, IIS mediates different biological effects in similar cells through similar downstream molecules, but at different developmental time points: adult hippocampal neurons respond with proliferation to Igf- 1 compared to embryonic hippocampal progenitors that need IIS for their survival. This summary indicates that we still need comprehensive analyses of overlapping or distinct target genes activated through overlapping or distinct signalling pathways during development and in the various cell types of the CNS.

The study of Otaegi et al. of IIS in OBSC also elaborates on downstream signalling by showing that Igf- 1 treatment increases phosphorylation of Akt at Ser473 as well as Thr308 which is associated with increased proliferation and neural differentiation [54] (Fig. 11). Pten, that antagonises PI3-kinase induced phosphorylation of phosphatidylinositol $(3,4,5)$ trisphosphate (PtdIns(3,4,5)P3), reduces basal levels of the activating posttranslational modifications of Akt, which are however overridden by presence of Insulin/Igf-1. Nevertheless, overexpression of Pten impaires neural differentiation without affecting progenitor proliferation, and overexpression of a mutant Pten increases OBSC differentiation. Direct inhibition of PI3-kinase through LY294002 interferes with Igf-1-stimulated Akt-phosphorylation and resultes in impaired proliferation as well as neural differentiation. Thus, OBSC differentiation is under control of basic levels of pAkt while increased pAkt-levels through IIS activation affect additionally proliferation.

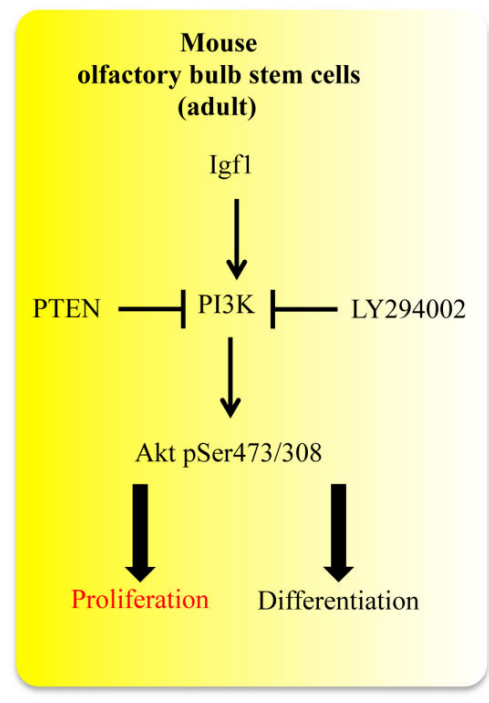

Figure 11. IIS affects proliferation and differentiation in adult OBSC [51].

Early postnatal olfactory bulb neurons do survive upon Igf-1-signalling. In this context, a positive feedback has been proposed between Igf- 1 and Bcl-2. Igf-1 increases expression 
of anti-apoptotic Bcl-2, and overexpression of Bcl-2 in vivo results in increased Igf-1 and Igfbp2 [103].

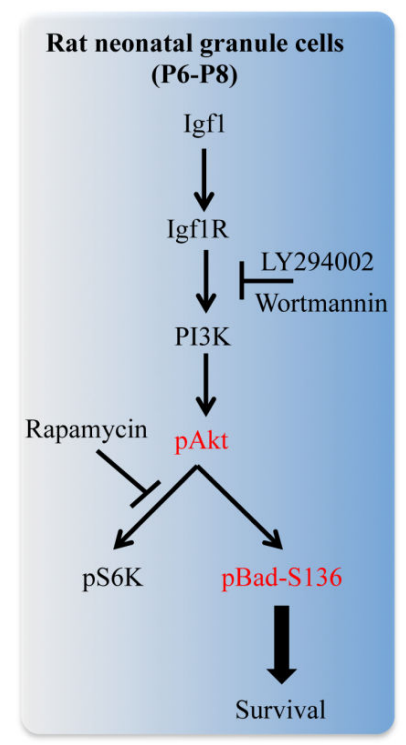

Figure 12. Survival of CGN upon IIS [90, 104, 105].

Igf-1 action as survival factor for postnatal cerebellar granule neurons (CGN) requires different intracellular signalling [90]. In this context, Igf-1 activation of PI3K leads to inhibition of Erk as well as Caspase-3, two pathways exerting different events in cell death, plasma membrane damage and DNA break-down, respectively. Activated PI3K phosphorylates not only Akt but also Protein kinase A (PKA). Whereas pAkt activates Caspase-3 and is leading to DNA breakdown, PKA suppresses sustained Erk activation via phosphorylation of cRaf at Ser259 and prevents plasma membrane damage (Fig. 12).

Further studies of Igf-1-dependent survival of rat CGN links PI3K activation of Akt to phosphorylation of Bad at Ser136 that is responsible for releasing anti-apoptotic Bcl- $\mathrm{X}_{\mathrm{L}}$ $[104,105]$. This finding is partially corroborated in vivo, where Igf- 1 overexpression results in increased levels of Bcl- $X_{\mathrm{L}}$ at early time points (P7) and decreased expression of pro-apoptotic Bax and Bad at P14 and P21. However, the investigation of the phosphorylation status of Bad in vivo was not conclusive [92].

Oligodendrogenesis and initiation as well as maintenance of myelination are strongly dependent on IIS. Several mouse models in which normal IIS was manipulated display phenotypes affecting oligodendroglial cells: overexpression of Igf-1 driven by diverse promoters or administration of Igf-1 into the CSF result in increased numbers of oligodendrocytes and myelination [106-108], while loss of Igf-1 leads to impaired and lost myelination [109]. IIS in oligodendrocytes and their precursors is dependent on signalling over the Igf- $1 \mathrm{r}$, since Igf- $1 \mathrm{r}$ - 
deficient mice show retarded growth and initiation of myelination [110]. This phenotype is not observed in IR-deficient mice and is thus mediated through Igf-1r-signalling [111]. IIS depends on binding of insulin-response substrate (Irs1-4) to the receptors, which results in their respective phosphorylation.

Proliferation of oligodendroglial rat precursors increases in response to Igf- 1 and is mediated over a prolonged time period by Pdk-1, Akt Thr308 as well as Ser473 phosphorylation, and pGsk-3 $\beta$. Igf-1 treatment also activated the Ras/MAPK-pathway as evidenced by increased pErk-1/-2, following a fast kinetic over a short period of time [112]. Inhibition of upstream signalling molecules revealed concerted involvement of PI3K, MAPK as well as Src-kinase in cell cycle progression, and predominance of Akt-mediated signalling. Although so far ill defined, cross-talk among the different signalling pathways activated through Igf- 1 is a likely scenario resulting from this study. In continuation of this study it was observed that Igf-1 increases protein synthesis by signalling through PI3K-Akt-mTor-p70S6K-4E-BP1 as well as by activating Ras/MAPK [113]. Transcription was a prerequisite for mTor-1-dependent protein synthesis upon Igf-1 in proliferating oligodendroglial precursors. Early differentiation of the precursors upon Igf-1 also involves transcriptional processes, however subsequent terminal differentiation is independent. This finding indicates different roles for Igf- 1 during oligodendroglial cell development.

Further analyses of these potential downstream signalling components reveal that initiation of myelination is coupled to the activity of Irs-2 but not to Irs-1. Irs-2-deficient mice display a defect in timing of myelination and this effect can not be compensated through a simultaneous upregulation of Igf-1r and Irs-1 expression as well as signalling in these mice [111]. Increased Igf-1r signalling is shown through increased levels of pAkt, pGsk-3 $\beta$ and pErk-1/2.

Igf-2 influences proliferation of adult DG progenitors [88]. In this study, knockdown of Igf-2 results in decreased mitosis that is paired with reduced phosphorylation of Irs- 1 and Akt. This phenotype is rescued through overexpression of a dominant-active Akt. Blocking of Igf-1rsignalling reduces proliferation that exceeds the drop observed after Igf- 2 knockdown. This indicates that NPC proliferation in the adult DG is influenced through Igf- 1 and Igf-2 ligands that signal both through the Igf-1r onto Akt.

Signalling of Igf-2 through its cognate Igf-2r has been shown to be important for neuronal maturation with regard to synapse density and spine morphology [14]. Downstream signals included the activation of MAPK/Erk- pathway, since changes at the level of the synapses were inhibited through PD98059.

Igf-2 dependent memory enhancement in adult rat hippocampus requires signalling via the Igf-2r [13]. This Igf-2 effect is associated with de novo protein synthesis. Further analyses of the downstream signalling cascade reveales involvement of Gsk-3 $\beta$, since the Igf-2-specific effect is blocked by the presence of the Gsk-3 $\beta$-inhibitor SB216763. It was shown that this cascade does not act on a widespread cell level but that it mainly regulates molecular events at specific synapses, e.g. synapses that are "transcriptionally marked" through training. Igf-2 results in increased synaptic activity as revealed by stable long-term potentiation (LTP). The underlying 
mechanism is therefore deduced to include Igf-2-dependent activation of Gsk-3 $\beta$ that leads to synaptic mobilisation and expression of the AMPA-receptor GluR1.

Igf-2 is further under control of NF- $\kappa B$ transcription factors. Nuclear import of NF- $\kappa B$ is prevented by $I \kappa B$ proteins, which are degraded upon activation of the I $\kappa B$ kinase (IKK) complex. This proteasomal event releases NF- $\kappa \mathrm{B}$ into the nucleus. In the adult mouse hippocampus, synaptic IKK/NF- $\kappa \mathrm{B}$ signalling is important for function and maturation. Recent data show that Igf-2 is under control of NF- $\mathrm{BB}$-mediated transcriptional regulation [14]. This study shows that Igf-2 increases the number of synapses and of mature spines in vitro, while Igf- 1 does only have moderate effects in this assay. The Igf- 2 effect is predominantly transduced via the Igf-2r and is prevented through MEK inhibitor PD98059, but not through inhibition of Gsk-3 $\beta$ or p38 activity. Corroborating these findings in vivo, mice with deficient IKK-2 show reduced Igf-2 expression and pErk1/2 levels [14].

Igf-2-dependent proliferation of mouse CGP is associated with activation of PI3K, but also with mTorc- 2 activity that is obvious from increased Akt Ser473 phosphorylation [57]. IIS downstream signalling is followed up to Gsk-3 $\beta$ in this cellular context.

\section{Insulin/IGF-signalling cross-talk}

\subsection{Signalling cross-talk in the central nervous system}

In vivo, it is very unlikely that growth factors act alone, but a more likely scenario is the presence of a plethora of signalling molecules and that a phenotypic consequence is a complicated interplay of various signalling pathways. Special emphasise is given to know interactions and cross-talks between such pathways involving IIS, although this is only an emerging field that awaits further studies.

Cultured NPC from the rat adult SVZ respond with neuronal differentiation upon various single stimuli, like Fgf-2, Bdnf, Ngf, and Igf-1. When Fgf-2, Bdnf, and Ngf are applied in combination with Igf- 1 , significant increases in the number of neurons are observed, indicating synergistic action upon neuronal differentiation [114]. Another study uses immobilised growth factors, alone and in different combinations, on which the authors plated NPC from embryonic rat striatum. Proliferation, neuronal as well as glial differentiation is assessed and reveals that Igf- 1 alone mainly drives neuronal differentiation and does not affect proliferation or glial differentiation significantly. In combination with Fgf-2, Igf-1 only slightly increases progenitor states and proliferation, and this effect is even smaller in combination with Egf that also acts mitotic in single treatments. Bdnf increases neuronal differentiation alone, as does Igf- 1 , however the combination of the two factors results in fewer neurons than single treatments. The differentiation potential of Igf- 1 alone is also lowered by presence of the mitotic growth factors Fgf-2 and Egf. Igf-1 alone does not induce glial differentiation. In combination with $\mathrm{Cntf}$ that induces astrocytic phenotypes alone, Igf-1 decreases Cntf-mediated differentiation [115]. 
The cross-talk of IIS with regard to Fgf-2- as well as Egf-signalling mainly influences stem cell proliferation, but whether it is synergistically is not yet totally clear $[47,49,50,51,52]$. A putative scenario might be that Igf-1 keeps progenitors in a healthy or fit state in which they are ready for further cell divisions, for which Fgf-2 or Egf are the instructive cues. However, withdrawal of Fgf-2 is a prerequisite for neuronal differentiation upon Igf-1 presence [85]. Synergistically, Igf-1-signalling seems to increase the effects of Fgf- 2 on NPC proliferation as has been shown in rat adult hippocampal cells. This effect is dependent on PI3K that is activated upon Fgf-2 treatment [99].

Survival of CNS-derived cells is one of the major and comprehensive effects of IIS in the developing and adult organism. IIS is only one of several pathways that influence survival, and thus cross-talk with other pathways might be of principal importance. Bdnf-mediated signalling is one of such pathways that are studied with regard to IIS. No additive function of Bdnf- and Igf-1-mediated survival is reported from different cellular sources [102,116], however other data is contradictory in finding additive affects on prenatal rat hippocampal cell survival [117] that cumulate on increased pGsk-3 $\beta$. Consistently reported is a stronger survival effect under serum-deprivation for IIS compared to Bdnf. The underlying signalling might again diverge in different cellular systems: hippocampal neurons survive upon Igf-1 and Bdnf through induction of the PI3K-pAkt branch and survival is blocked by LY294002. Activity of the MAPK-pErk1/2 branch does not mediate survival. However, cortical neurons that also depend much stronger on IIS than on Bdnf-signalling for their survival also activate the PI3K-pAkt branch [117], but LY294002 does not completely attribute for survival upon IIS. In addition, Src-kinase is activated in these cortical neurons upon Igf-1, corroborating the finding of an involvement of Pac1-r-signalling in IIS-mediated survival in cortical neurons [91]. Nevertheless, Bdnf and IIS have additive effects in the activation of PI3-K, although this is not detectable on the level of the number of surviving cells. This finding strongly suggests that IIS is overriding the effects of Bdnf in survival of CNS-derived cells. However, one Bdnf effect on hippocampal as well as cortical neurons is to slightly activate Irs-1 and -2 phosphorylation, indicating a potential cross-activation of IIS through Bdnf. Whether this cross-activation is of physiological significance in the presence of Igf-1, remains to be determined.

Studies of neural cell proliferation provide evidence of IIS cross-talk with the Wnt/ $\beta$-catenin pathway. Nestin-expressing neural progenitors as well as oligodendrocytes express different levels of $\beta$-catenin upon Igf-1 deletion or treatment $[118,119]$. In vitro, Igf- 1 induces increase of $\beta$-catenin as well as CycD1 expression in a PI3K-Akt kinases dependent manner in cultured oligodendrocytes. $\beta$-catenin is also known to activate $\mathrm{CycD} 1$ and thus defines a point of intersection between IIS and Wnt signalling [118]. Impaired proliferation of NPCs is observed after inactivation of the Igf-1r in Nestin-positive cells. Such NPCs of prenatal mouse brains are dependent on Wnt-signalling when proliferating, and Igf- $1 \mathrm{r}$ inactivation results in decreased levels of Gsk-3 $\beta$ and $\beta$-catenin, but with increased levels of the Wnt-receptor Frizzeled 3 and Wnt3a. While the former expression changes are influenced through the Igf-1/PI3K/Aktpathway, increased levels of Frizzeled 3 and Wnt3a are thought to reflect a compensatory regulation stimulated by low levels of $\beta$-catenin. Inactivation of Gsk- $3 \beta$ in this setting reverts $\beta$-catenin levels and overcomes the block of proliferation as consequence of Igf- 1 r inactivation. 
Overexpression of Igf- 1 increases $\beta$-catenin-levels and stimulates progenitor proliferation [119]. These experiments clearly establish an important cross-talk to regulate progenitor proliferation in the developing brain.

IIS has also been described to cross-talk with the Tgf $\beta$-pathway in numerous systems [120]. However, a comprehensive analysis of the multiple points of intersections was not published yet for the nervous system. In a general view, Tgf $\beta$-ligands 1, 2, and 3 exert opposing effects compared to IIS. This has been shown for the potential of NPC proliferation and differentiation [121] upon Tgf $\beta$-treatment, since these cells stop proliferating and initiate neuronal differentiation in mouse E16.5 hippocampus and cerebral cortex, in vitro and in vivo. Proliferation and differentiation of ESCs are also influenced in opposite ways through IIS or Tgf $\beta$-signalling. Smad4-deficient ESC show increased neuronal differentiation, and hereby preferentially in neuronal lineages of the mid- and anterior hindbrain [122]. Further, more serotonergic neurons of the dorsal midbrain are observed in in vitro differentiated Smad4-deficient cultures. However, Smad4 is a transcriptional mediator of several members of the $\operatorname{Tgf} \beta$-superfamiliy, including Activin-, Gdf-, Nodal-, Tgf $\beta$ - as well as Bmp-signalling. Thus, direct correlation to one specific signalling pathway is not achieved in this study. Neural induction of human ESCs is also increased in the presence of the Alk4,5,7 inhibitor SB431542 that interferes with Activin-, Gdf- and Nodal-signalling apart from Tgf $\beta$. Increased differentiation into the neural lineage is assessed by Pax-6 expression which is accompanied by decreased Bmp-4 and increased Noggin expression. These dynamics point to a contribution of several members of the Tgf $\beta$ superfamily of which the Bmp branch has a major contribution [123], but certainly does not act alone. Of further note, neuronal differentiation of ESC cells is not solely dependent on signalling of the above mentioned members of the $\operatorname{Tgf} \beta$-superfamily, since deletion of the common effector Smad4 in ESC does not completely abolish the potential for neuronal differentiation [122]. In contrast, IIS keeps ESCs in a proliferative state and is necessary for selfrenewal. Whether both pathways cross-talk to suppress the respective other one is not investigated so far, but might be a likely scenario, given the connections described in other cellular lineages.

FoxO and Smad proteins interact and the FoxO/Smad complex is implicated in transcriptional control in early mouse cortical NPCs, thereby defining one point of intersection of IIS and $\operatorname{Tgf} \beta$. Smad 2 and 3 transcriptions factors are part of the canonical Tgf $\beta$-signalling pathway and are phosphorylated upon binding of $\operatorname{Tgf} \beta$-ligands to the $\operatorname{Tgf} \beta$-receptor 1 and 2 . The phosphorylated proteins bind to $\operatorname{Smad} 4$ and together translocate to the nucleus. This Smad complex interacts with FoxO1, 3a, and 4, three TF of the forkhead family that are under influence of IIS. Upon activation of the Igf-1r, FoxO TF are phosphorylated in a PI3K-Akt-dependent manner. This phosphorylation leads to retention of FoxO proteins in the cytoplasm. Thus, IIS opposes transcriptional control through the $\operatorname{Tgf} \beta$-pathway by interfering with translocation of cofactors into the nucleus [124].

While survival of cerebellar granule precursors depends on IIS, control of CGP proliferation indicates cross-talk of IIS and Shh-signalling [34,55,125]. Igf/Shh interaction is reported to occur on various levels. The study of Fernandez et al. (2010) suggests that IIS via Igf-1r increases Shhmediated proliferation, but IIS-mediated proliferation is independent on Shh-signalling. In 
this setting, Igfbp-5 interfered with Shh-mediated cell proliferation. Igf-2-signalling increases levels of Gli-1, a transcription factor that is mainly activated through Shh-signalling. Gli-1 as well as Gsk-3 $\beta$ are regulators of $\mathrm{CycD} 1$, which might be another point of intersection between these two signalling pathways besides regulation of Shh-target Nmyc-1 through Gsk-3 $\beta$ $[57,126]$. Parathath and colleagues established a role for Irs- 1 and mTorc- 1 upon Shh-mediated CGP proliferation. This study shows specific upregulation of Irs-1 protein upon Shh that does not result in the activation of Akt. Knockdown of Irs-1 abolishes Shh-mediated CGP proliferation, which is in turn activated upon Irs-1 overexpression. Irs-1 overexpression increases or maintains expression levels of $\mathrm{CycD} 2$ and Nmyc-1, which are implicated in cell cycle control. Irs-1 protein stability in CGP is controlled by the negative feed back loop, in which mTorc-1activation induces p70S6K that phosphorylates Irs- 1 and targets Irs- 1 for degradation. Shhdependent increase in Irs-1 is dependent on mTorc-1-inhibition that is followed by suppression of p70S6K-kinase activity [125]. In contrast to this study, Hartmann et al. [57] postulated PI3K/ Akt- and synergistically Shh-dependent transcriptional control of Gli-1 and CycD1 as possible lines of interaction.

Although these data corroborate tight connections between Shh and IIS, there is need for further mechanistic investigation to define further knots in the signalling network.

\section{Concluding remarks}

As pointed out through the many studies of IIS in the CNS, this signalling pathway has an essential role for development and function of this organ. Albeit studied in many laboratories, our understanding of this central signalling pathway is far from being complete. Still we do not understand how the same biological function is achieved by activating different downstream cascades and why it is necessary to have these multiple pathways that respond to one stimulus. We also do not know why different biological functions are the consequence of IIS at different developmental time points in cells from the same part of the brain. In this light it is of major interest that studies are emerging that focus on cross-talks of various stimuli. Exposure to multiple stimuli at a time probably reflects more the natural environment of a developing and mature neural cell than exposure to one single growth factor. It is also of major interest to dissect different functions during development and to define the molecular players involved into functional switches. In this regard it will be important to dissect different subcomplexes of PI3Ks or Akts that might be implicated in IIS. It will be also needed to carefully analyse the balances between the different branches of the signalling cascades and to identify and close further gaps that might be still in the pathways as they are commonly described today. Given the central role of IIS in body development, growth and maintenance, this knowledge will be of utmost interest and will also be exploited for therapeutic medicine in various contexts. 


\section{Nomenclature and abbreviations}

CA - Cornu ammonis, CGN - Cerebellar granule neurons, CGP - Cerebellar granule precursor, CNS - Central nervous system, CSF - Cerebrospinal fluid, DG - dentate gyrus, ESC - Embryonic Stem Cell, GH - Growth hormone, IIS - Insulin/Igf-signalling, Igf - Insulin like growth factor 1, Igfbp - Insulin like growth factor binding protein, Ir - Insulin receptor, mTOR - mammalian target of rapamycin, NSC - Neural Stem Cell, NPC - Neural Progenitor cell, OB - Olfactory Bulb, OBSC - Olfactory Bulb stem cell, p - phospho-, SGZ - Subgranular zone, SVZ - Subventricular zone, TF - Transcription factor.

\section{Acknowledgements}

The author gratefully thanks Dr. K. Thedieck, Dept. of Biology III, Albert-Ludwigs-University Freiburg for conceptualising and discussing this review. I also thank S. Wahane, Dept. of Molecular Embryology, Albert-Ludwigs-University Freiburg for preparing figures for this review.

\section{Author details}

Tanja Vogel

Dept. of Molecular Embryology, Institute for Anatomy and Cell Biology, Albert-LudwigsUniversity Freiburg, Germany

\section{References}

[1] Fernandez AM, Torres-Aleman I. The many faces of insulin-like peptide signalling in the brain. Nat Rev Neurosci. 2012;13(4):225-39.

[2] Pandini G, Frasca F, Mineo R, Sciacca L, Vigneri R, Belfiore A. Insulin/insulin-like growth factor I hybrid receptors have different biological characteristics depending on the insulin receptor isoform involved. J. Biol. Chem. 2002;277(42):39684-95.

[3] Kim JG, Kang MJ, Yoon Y-K, Kim H-P, Park J, Song S-H, et al. Heterodimerization of glycosylated insulin-like growth factor-1 receptors and insulin receptors in cancer cells sensitive to anti-IGF1R antibody. PLoS ONE. 2012;7(3):e33322.

[4] Chiu S-L, Cline HT. Insulin receptor signaling in the development of neuronal structure and function. Neural Dev. 2010;5:7. 
[5] Werner H, Weinstein D, Bentov I. Similarities and differences between insulin and IGF-I: structures, receptors, and signalling pathways. Arch. Physiol. Biochem. 2008;114(1):17-22.

[6] Anderson KE, Jackson SP. Class I phosphoinositide 3-kinases. Int. J. Biochem. Cell Biol. 2003;35(7):1028-33.

[7] Pearce LR, Komander D, Alessi DR. The nuts and bolts of AGC protein kinases. Nat. Rev. Mol. Cell Biol. 2010;11(1):9-22.

[8] Dalle Pezze P, Sonntag AG, Thien A, Prentzell MT, Gödel M, Fischer S, et al. A dynamic network model of mTOR signaling reveals TSC-independent mTORC2 regulation. Sci Signal. 2012;5(217):ra25.

[9] Gehart H, Kumpf S, Ittner A, Ricci R. MAPK signalling in cellular metabolism: stress or wellness? EMBO reports. 2010;11(11):834-40.

[10] Taniguchi CM, Aleman JO, Ueki K, Luo J, Asano T, Kaneto H, et al. The p85alpha regulatory subunit of phosphoinositide 3-kinase potentiates c-Jun N-terminal kinasemediated insulin resistance. Molecular and Cellular Biology. 2007;27(8):2830-40.

[11] Asada S, Daitoku H, Matsuzaki H, Saito T, Sudo T, Mukai H, et al. Mitogen-activated protein kinases, Erk and p38, phosphorylate and regulate Foxo1. Cell. Signal. 2007;19(3):519-27.

[12] Russo VC, Gluckman PD, Feldman EL, Werther GA. The insulin-like growth factor system and its pleiotropic functions in brain. Endocrine Reviews. 2005;26(7):916-43.

[13] Chen DY, Stern SA, Garcia-Osta A, Saunier-Rebori B, Pollonini G, Bambah-Mukku D, et al. A critical role for IGF-II in memory consolidation and enhancement. Nature. 2011;469(7331):491-7.

[14] Schmeisser MJ, Baumann B, Johannsen S, Vindedal GF, Jensen V, Hvalby ØC, et al. $\mathrm{I} \kappa \mathrm{B}$ kinase/nuclear factor $\kappa \mathrm{B}$-dependent insulin-like growth factor 2 (Igf2) expression regulates synapse formation and spine maturation via Igf2 receptor signaling. Journal of Neuroscience. 2012;32(16):5688-703.

[15] Rajaram S, Baylink DJ, Mohan S. Insulin-like growth factor-binding proteins in serum and other biological fluids: regulation and functions. Endocrine Reviews. 1997;18(6):801-31.

[16] Bondy C, Werner H, Roberts CT, LeRoith D. Cellular pattern of type-I insulin-like growth factor receptor gene expression during maturation of the rat brain: comparison with insulin-like growth factors I and II. NSC. 1992;46(4):909-23.

[17] Bondy CA, Lee WH. Patterns of insulin-like growth factor and IGF receptor gene expression in the brain. Functional implications. Ann. N. Y. Acad. Sci. 1993;692:33-43. 
[18] Werther GA, Abate M, Hogg A, Cheesman H, Oldfield B, Hards D, et al. Localization of insulin-like growth factor-I mRNA in rat brain by in situ hybridization--relationship to IGF-I receptors. Mol Endocrinol. 1990;4(5):773-8.

[19] Zhang J, Moats-Staats BM, Ye P, D'Ercole AJ. Expression of insulin-like growth factor system genes during the early postnatal neurogenesis in the mouse hippocampus. J. Neurosci. Res. 2007;85(8):1618-27.

[20] Chernausek SD, Murray MA, Cheung PT. Expression of insulin-like growth factor binding protein-4 (IGFBP-4) by rat neural cells--comparison to other IGFBPs. Regul. Pept. 1993;48(1-2):123-32.

[21] Wood TL, Streck RD, Pintar JE. Expression of the IGFBP-2 gene in post-implantation rat embryos. Development. 1992;114(1):59-66.

[22] Lee WH, Michels KM, Bondy CA. Localization of insulin-like growth factor binding protein-2 messenger RNA during postnatal brain development: correlation with insulin-like growth factors I and II. NSC. 1993;53(1):251-65.

[23] Holmes KM, Annala M, Chua CYX, Dunlap SM, Liu Y, Hugen N, et al. Insulin-like growth factor-binding protein 2-driven glioma progression is prevented by blocking a clinically significant integrin, integrin-linked kinase, and NF- $\kappa$ B network. Proc. Natl. Acad. Sci. U.S.A. National Academy of Sciences; 2012;109(9):3475-80.

[24] Rorive S, Berton A, D'haene N, Takacs CN, Debeir O, Decaestecker C, et al. Matrix metalloproteinase-9 interplays with the IGFBP2-IGFII complex to promote cell growth and motility in astrocytomas. Glia. 2008;56(15):1679-90.

[25] Ikonen M, Liu B, Hashimoto Y, Ma L, Lee K-W, Niikura T, et al. Interaction between the Alzheimer's survival peptide humanin and insulin-like growth factor-binding protein 3 regulates cell survival and apoptosis. Proc. Natl. Acad. Sci. U.S.A. 2003;100(22):13042-7.

[26] Liu B, Lee HY, Weinzimer SA, Powell DR, Clifford JL, Kurie JM, et al. Direct functional interactions between insulin-like growth factor-binding protein-3 and retinoid $X$ receptor-alpha regulate transcriptional signaling and apoptosis. J. Biol. Chem. 2000;275(43):33607-13.

[27] Stenvers KL, Zimmermann EM, Gallagher M, Lund PK. Expression of insulin-like growth factor binding protein- 4 and -5 mRNAs in adult rat forebrain. J. Comp. Neurol. 1994;339(1):91-105.

[28] Kang DW, Chung YH, Lee JC, Bang JS, Kim D, Kim SS, et al. Immunohistochemical study on the distribution of insulin-like growth factor-binding protein 4 in the central nervous system of SOD1(G93A) transgenic mice as an in vivo model of amyotrophic lateral sclerosis. Ann. Anat. 2008;190(6):502-9. 
[29] Naeve GS, Vana AM, Eggold JR, Verge G, Ling N, Foster AC. Expression of rat insulin-like growth factor binding protein-6 in the brain, spinal cord, and sensory ganglia. Brain Res. Mol. Brain Res. 2000;75(2):185-97.

[30] Bienvenu G, Seurin D, Grellier P, Froment P, Baudrimont M, Monget P, et al. Insulinlike growth factor binding protein- 6 transgenic mice: postnatal growth, brain development, and reproduction abnormalities. Endocrinology. 2004;145(5):2412-20.

[31] Agis-Balboa RC, Arcos-Diaz D, Wittnam J, Govindarajan N, Blom K, Burkhardt S, et al. A hippocampal insulin-growth factor 2 pathway regulates the extinction of fear memories. The EMBO Journal. 2011;30(19):4071-83.

[32] Werther GA, Hogg A, Oldfield BJ, McKinley MJ, Figdor R, Allen AM, et al. Localization and characterization of insulin receptors in rat brain and pituitary gland using in vitro autoradiography and computerized densitometry. Endocrinology. 1987;121(4): $1562-70$

[33] Unger J, McNeill TH, Moxley RT, White M, Moss A, Livingston JN. Distribution of insulin receptor-like immunoreactivity in the rat forebrain. NSC. 1989;31(1):143-57.

[34] Fernandez C, Tatard VM, Bertrand N, Dahmane N. Differential modulation of Sonichedgehog-induced cerebellar granule cell precursor proliferation by the IGF signaling network. Dev Neurosci. 2010;32(1):59-70.

[35] Wang L, Schulz TC, Sherrer ES, Dauphin DS, Shin S, Nelson AM, et al. Self-renewal of human embryonic stem cells requires insulin-like growth factor-1 receptor and ERBB2 receptor signaling. Blood. 2007;110(12):4111-9.

[36] Watanabe S, Umehara H, Murayama K, Okabe M, Kimura T, Nakano T. Activation of Akt signaling is sufficient to maintain pluripotency in mouse and primate embryonic stem cells. Oncogene. 2006;25(19):2697-707.

[37] Armstrong L, Hughes O, Yung S, Hyslop L, Stewart R, Wappler I, et al. The role of PI3K/AKT, MAPK/ERK and NFkappabeta signalling in the maintenance of human embryonic stem cell pluripotency and viability highlighted by transcriptional profiling and functional analysis. Human Molecular Genetics. 2006;15(11):1894-913.

[38] McLean AB, D'Amour KA, Jones KL, Krishnamoorthy M, Kulik MJ, Reynolds DM, et al. Activin a efficiently specifies definitive endoderm from human embryonic stem cells only when phosphatidylinositol 3-kinase signaling is suppressed. Stem Cells. 2007;25(1):29-38.

[39] Vazin T, Becker KG, Chen J, Spivak CE, Lupica CR, Zhang Y, et al. A novel combination of factors, termed SPIE, which promotes dopaminergic neuron differentiation from human embryonic stem cells. PLoS ONE. 2009;4(8):e6606.

[40] Chen L, Khillan JS. A novel signaling by vitamin A/retinol promotes self renewal of mouse embryonic stem cells by activating PI3K/Akt signaling pathway via insulinlike growth factor-1 receptor. Stem Cells. 2010;28(1):57-63. 
[41] Freund C, Oostwaard DW-V, Monshouwer-Kloots J, van den Brink S, van Rooijen M, $\mathrm{Xu} \mathrm{X}$, et al. Insulin redirects differentiation from cardiogenic mesoderm and endoderm to neuroectoderm in differentiating human embryonic stem cells. Stem Cells. 2008;26(3):724-33.

[42] Brüning JC, Gautam D, Burks DJ, Gillette J, Schubert M, Orban PC, et al. Role of brain insulin receptor in control of body weight and reproduction. Science. 2000;289(5487):2122-5.

[43] Arsenijevic $Y$, Weiss S. Insulin-like growth factor-I is a differentiation factor for postmitotic CNS stem cell-derived neuronal precursors: distinct actions from those of brain-derived neurotrophic factor. J. Neurosci. 1998;18(6):2118-28.

[44] Ajo R, Cacicedo L, Navarro C, Sánchez-Franco F. Growth hormone action on proliferation and differentiation of cerebral cortical cells from fetal rat. Endocrinology. 2003;144(3):1086-97.

[45] Mairet-Coello G, Tury A, DiCicco-Bloom E. Insulin-like growth factor-1 promotes $\mathrm{G}(1) / S$ cell cycle progression through bidirectional regulation of cyclins and cyclindependent kinase inhibitors via the phosphatidylinositol 3-kinase/Akt pathway in developing rat cerebral cortex. Journal of Neuroscience. 2009Jan.21;29(3):775-88.

[46] Zheng W-H, Kar S, Quirion R. Insulin-like growth factor-1-induced phosphorylation of transcription factor FKHRL1 is mediated by phosphatidylinositol 3-kinase/Akt kinase and role of this pathway in insulin-like growth factor-1-induced survival of cultured hippocampal neurons. Mol. Pharmacol. 2002;62(2):225-33.

[47] Drago J, Murphy M, Carroll SM, Harvey RP, Bartlett PF. Fibroblast growth factormediated proliferation of central nervous system precursors depends on endogenous production of insulin-like growth factor I. Proc. Natl. Acad. Sci. U.S.A. 1991;88(6): 2199-203.

[48] DiCicco-Bloom E, Black IB. Insulin growth factors regulate the mitotic cycle in cultured rat sympathetic neuroblasts. Proc. Natl. Acad. Sci. U.S.A. 1988;85(11):4066-70.

[49] Arsenijevic Y, Weiss S, Schneider B, Aebischer P. Insulin-like growth factor-I is necessary for neural stem cell proliferation and demonstrates distinct actions of epidermal growth factor and fibroblast growth factor-2. Journal of Neuroscience. 2001;21(18):7194-202.

[50] Kalluri HSG, Vemuganti R, Dempsey RJ. Mechanism of insulin-like growth factor Imediated proliferation of adult neural progenitor cells: role of Akt. Eur J Neurosci. 2007;25(4):1041-8.

[51] Sato A, Sunayama J, Matsuda K-I, Tachibana K, Sakurada K, Tomiyama A, et al. Regulation of neural stem/progenitor cell maintenance by PI3K and mTOR. Neurosci. Lett. 2010;470(2):115-20.

[52] Vicario-Abejón C, Yusta-Boyo MJ, Fernández-Moreno C, de Pablo F. Locally born olfactory bulb stem cells proliferate in response to insulin-related factors and require 
endogenous insulin-like growth factor-I for differentiation into neurons and glia. Journal of Neuroscience. 2003;23(3):895-906.

[53] Han J, Wang B, Xiao Z, Gao Y, Zhao Y, Zhang J, et al. Mammalian target of rapamycin (mTOR) is involved in the neuronal differentiation of neural progenitors induced by insulin. Mol. Cell. Neurosci. 2008;39(1):118-24.

[54] Otaegi G, Yusta-Boyo MJ, Vergaño-Vera E, Méndez-Gómez HR, Carrera AC, Abad JL, et al. Modulation of the PI 3-kinase-Akt signalling pathway by IGF-I and PTEN regulates the differentiation of neural stem/precursor cells. Journal of Cell Science. 2006;119(Pt 13):2739-48.

[55] Ye P, Xing Y, Dai Z, D'Ercole AJ. In vivo actions of insulin-like growth factor-I (IGF-I) on cerebellum development in transgenic mice: evidence that IGF-I increases proliferation of granule cell progenitors. Brain Res. Dev. Brain Res. 1996;95(1):44-54.

[56] Lin X, Bulleit RF. Insulin-like growth factor I (IGF-I) is a critical trophic factor for developing cerebellar granule cells. Brain Res. Dev. Brain Res. 1997;99(2):234-42.

[57] Hartmann W, Koch A, Brune H, Waha A, Schüller U, Dani I, et al. Insulin-like growth factor II is involved in the proliferation control of medulloblastoma and its cerebellar precursor cells. The American Journal of Pathology. 2005;166(4):1153-62.

[58] Nitta A, Zheng W-H, Quirion R. Insulin-like growth factor 1 prevents neuronal cell death induced by corticosterone through activation of the PI3k/Akt pathway. J. Neurosci. Res. 2004;76(1):98-103.

[59] Moosavi M, Maghsoudi N, Zahedi-Asl S, Naghdi N, Yousefpour M, Trounce IA. The role of PI3/Akt pathway in the protective effect of insulin against corticosterone cell death induction in hippocampal cell culture. Neuroendocrinology. 2008;88(4):293-8.

[60] Hodge RD, D'Ercole AJ, O'Kusky JR. Insulin-like growth factor-I accelerates the cell cycle by decreasing G1 phase length and increases cell cycle reentry in the embryonic cerebral cortex. Journal of Neuroscience. 2004;24(45):10201-10.

[61] Popken GJ, Hodge RD, Ye P, Zhang J, Ng W, O'Kusky JR, et al. In vivo effects of insulin-like growth factor-I (IGF-I) on prenatal and early postnatal development of the central nervous system. Eur J Neurosci. 2004;19(8):2056-68.

[62] Hodge RD, D'Ercole AJ, O'Kusky JR. Insulin-like growth factor-I (IGF-I) inhibits neuronal apoptosis in the developing cerebral cortex in vivo. Int. J. Dev. Neurosci. 2007;25(4):233-41.

[63] Hodge RD, D'Ercole AJ, O'Kusky JR. Increased expression of insulin-like growth factor-I (IGF-I) during embryonic development produces neocortical overgrowth with differentially greater effects on specific cytoarchitectonic areas and cortical layers. Brain Res. Dev. Brain Res. 2005;154(2):227-37. 
[64] Beck KD, Powell-Braxton L, Widmer HR, Valverde J, Hefti F. Igf1 gene disruption results in reduced brain size, CNS hypomyelination, and loss of hippocampal granule and striatal parvalbumin-containing neurons. Neuron. 1995;14(4):717-30.

[65] Carson MJ, Behringer RR, Brinster RL, McMorris FA. Insulin-like growth factor I increases brain growth and central nervous system myelination in transgenic mice. Neuron. 1993;10(4):729-40.

[66] Liu W, Ye P, O'Kusky JR, D'Ercole AJ. Type 1 insulin-like growth factor receptor signaling is essential for the development of the hippocampal formation and dentate gyrus. J. Neurosci. Res. 2009;87(13):2821-32.

[67] Ludwig T, Eggenschwiler J, Fisher P, D'Ercole AJ, Davenport ML, Efstratiadis A. Mouse mutants lacking the type 2 IGF receptor (IGF2R) are rescued from perinatal lethality in Igf2 and Igf1r null backgrounds. Developmental Biology. 1996;177(2):51735.

[68] Wang ZQ, Fung MR, Barlow DP, Wagner EF. Regulation of embryonic growth and lysosomal targeting by the imprinted Igf2/Mpr gene. Nature. 1994;372(6505):464-7.

[69] Lau MM, Stewart CE, Liu Z, Bhatt H, Rotwein P, Stewart CL. Loss of the imprinted IGF2/cation-independent mannose 6-phosphate receptor results in fetal overgrowth and perinatal lethality. Genes \&amp; Development. 1994;8(24):2953-63.

[70] DeChiara TM, Efstratiadis A, Robertson EJ. A growth-deficiency phenotype in heterozygous mice carrying an insulin-like growth factor II gene disrupted by targeting. Nature. 1990;345(6270):78-80.

[71] Dikkes P, B Jaffe D, Guo W-H, Chao C, Hemond P, Yoon K, et al. IGF2 knockout mice are resistant to kainic acid-induced seizures and neurodegeneration. Brain Research. 2007;1175:85-95.

[72] Lehtinen MK, Zappaterra MW, Chen X, Yang YJ, Hill AD, Lun M, et al. The cerebrospinal fluid provides a proliferative niche for neural progenitor cells. Neuron. 2011;69(5):893-905.

[73] Ni W, Rajkumar K, Nagy JI, Murphy LJ. Impaired brain development and reduced astrocyte response to injury in transgenic mice expressing IGF binding protein-1. Brain Research. 1997;769(1):97-107.

[74] D'Ercole AJ, Dai Z, Xing Y, Boney C, Wilkie MB, Lauder JM, et al. Brain growth retardation due to the expression of human insulin like growth factor binding protein-1 in transgenic mice: an in vivo model for the analysis of igf function in the brain. Brain Res. Dev. Brain Res. 1994;82(1-2):213-22.

[75] Schneider MR, Lahm H, Wu M, Hoeflich A, Wolf E. Transgenic mouse models for studying the functions of insulin-like growth factor-binding proteins. FASEB J. 2000;14(5):629-40. 
[76] Aberg MA, Aberg ND, Hedbäcker H, Oscarsson J, Eriksson PS. Peripheral infusion of IGF-I selectively induces neurogenesis in the adult rat hippocampus. Journal of Neuroscience. 2000;20(8):2896-903.

[77] Aberg MAI, Aberg ND, Palmer TD, Alborn A-M, Carlsson-Skwirut C, Bang P, et al. IGF-I has a direct proliferative effect in adult hippocampal progenitor cells. Mol. Cell. Neurosci. 2003;24(1):23-40.

[78] Choi Y-S, Cho H-Y, Hoyt KR, Naegele JR, Obrietan K. IGF-1 receptor-mediated ERK/ MAPK signaling couples status epilepticus to progenitor cell proliferation in the subgranular layer of the dentate gyrus. Glia. 2008;56(7):791-800.

[79] Trejo JL, Carro E, Torres-Aleman I. Circulating insulin-like growth factor I mediates exercise-induced increases in the number of new neurons in the adult hippocampus. Journal of Neuroscience. 2001;21(5):1628-34.

[80] Lichtenwalner RJ, Forbes ME, Sonntag WE, Riddle DR. Adult-onset deficiency in growth hormone and insulin-like growth factor-I decreases survival of dentate granule neurons: insights into the regulation of adult hippocampal neurogenesis. J. Neurosci. Res. 2006;83(2):199-210.

[81] Hsieh J, Aimone JB, Kaspar BK, Kuwabara T, Nakashima K, Gage FH. IGF-I instructs multipotent adult neural progenitor cells to become oligodendrocytes. The Journal of Cell Biology. 2004;164(1):111-22.

[82] O'Kusky JR, Ye P, D'Ercole AJ. Insulin-like growth factor-I promotes neurogenesis and synaptogenesis in the hippocampal dentate gyrus during postnatal development. Journal of Neuroscience. 2000;20(22):8435-42.

[83] Kalluri HSG, Dempsey RJ. IGFBP-3 inhibits the proliferation of neural progenitor cells. Neurochem. Res. 2011;36(3):406-11.

[84] Choi K-C, Yoo D-S, Cho K-S, Huh P-W, Kim D-S, Park C-K. Effect of single growth factor and growth factor combinations on differentiation of neural stem cells. J Korean Neurosurg Soc. 2008;44(6):375-81.

[85] Brooker GJ, Kalloniatis M, Russo VC, Murphy M, Werther GA, Bartlett PF. Endogenous IGF-1 regulates the neuronal differentiation of adult stem cells. J. Neurosci. Res. 2000;59(3):332-41.

[86] Russo VC, Bach LA, Fosang AJ, Baker NL, Werther GA. Insulin-like growth factor binding protein-2 binds to cell surface proteoglycans in the rat brain olfactory bulb. Endocrinology. 1997;138(11):4858-67.

[87] Hurtado-Chong A, Yusta-Boyo MJ, Vergaño-Vera E, Bulfone A, de Pablo F, VicarioAbejón C. IGF-I promotes neuronal migration and positioning in the olfactory bulb and the exit of neuroblasts from the subventricular zone. Eur J Neurosci. 2009;30(5): 742-55. 
[88] Bracko O, Singer T, Aigner S, Knobloch M, Winner B, Ray J, et al. Gene expression profiling of neural stem cells and their neuronal progeny reveals IGF2 as a regulator of adult hippocampal neurogenesis. Journal of Neuroscience. 2012;32(10):3376-87.

[89] Paik J-H, Ding Z, Narurkar R, Ramkissoon S, Muller F, Kamoun WS, et al. FoxOs cooperatively regulate diverse pathways governing neural stem cell homeostasis. Cell Stem Cell. 2009;5(5):540-53.

[90] Subramaniam S, Shahani N, Strelau J, Laliberte C, Brandt R, Kaplan D, et al. Insulinlike growth factor 1 inhibits extracellular signal-regulated kinase to promote neuronal survival via the phosphatidylinositol 3-kinase/protein kinase A/c-Raf pathway. Journal of Neuroscience. 2005;25(11):2838-52.

[91] Delcourt N, Thouvenot E, Chanrion B, Galéotti N, Jouin P, Bockaert J, et al. PACAP type I receptor transactivation is essential for IGF-1 receptor signalling and antiapoptotic activity in neurons. The EMBO Journal. 2007;26(6):1542-51.

[92] Chrysis D, Calikoglu AS, Ye P, D'Ercole AJ. Insulin-like growth factor-I overexpression attenuates cerebellar apoptosis by altering the expression of $\mathrm{Bcl}$ family proteins in a developmentally specific manner. Journal of Neuroscience. 2001;21(5):1481-9.

[93] Glasper ER, Llorens-Martin MV, Leuner B, Gould E, Trejo JL. Blockade of insulin-like growth factor-I has complex effects on structural plasticity in the hippocampus. Hippocampus. 2010;20(6):706-12.

[94] Niblock MM, Brunso-Bechtold JK, Riddle DR. Insulin-like growth factor I stimulates dendritic growth in primary somatosensory cortex. Journal of Neuroscience. 2000;20(11):4165-76.

[95] Laurino L, Wang XX, la Houssaye de BA, Sosa L, Dupraz S, Cáceres A, et al. PI3K activation by IGF-1 is essential for the regulation of membrane expansion at the nerve growth cone. Journal of Cell Science. 2005;118(Pt 16):3653-62.

[96] Sehat B, Tofigh A, Lin Y, Trocmé E, Liljedahl U, Lagergren J, et al. SUMOylation mediates the nuclear translocation and signaling of the IGF-1 receptor. Sci Signal. 2010;3(108):ra10.

[97] Sinor AD, Lillien L. Akt-1 expression level regulates CNS precursors. Journal of Neuroscience. 2004;24(39):8531-41.

[98] Endo M, Antonyak MA, Cerione RA. Cdc42-mTOR signaling pathway controls Hes5 and Pax6 expression in retinoic acid-dependent neural differentiation. J. Biol. Chem. 2009;284(8):5107-18.

[99] Peltier J, O'Neill A, Schaffer DV. PI3K/Akt and CREB regulate adult neural hippocampal progenitor proliferation and differentiation. Dev Neurobiol. 2007;67(10): 1348-61.

[100] Magri L, Cambiaghi M, Cominelli M, Alfaro-Cervello C, Cursi M, Pala M, et al. Sustained activation of mTOR pathway in embryonic neural stem cells leads to develop- 
ment of tuberous sclerosis complex-associated lesions. Cell Stem Cell. 2011;9(5):44762.

[101] Onda H, Crino PB, Zhang H, Murphey RD, Rastelli L, Gould Rothberg BE, et al. Tsc2 null murine neuroepithelial cells are a model for human tuber giant cells, and show activation of an mTOR pathway. Mol. Cell. Neurosci. 2002;21(4):561-74.

[102] Zheng W-H, Quirion R. Comparative signaling pathways of insulin-like growth factor-1 and brain-derived neurotrophic factor in hippocampal neurons and the role of the PI3 kinase pathway in cell survival. J Neurochem. 2004;89(4):844-52.

[103] Baker NL, Carlo Russo V, Bernard O, D'Ercole AJ, Werther GA. Interactions between bcl-2 and the IGF system control apoptosis in the developing mouse brain. Brain Res. Dev. Brain Res. 1999;118(1-2):109-18.

[104] Datta SR, Dudek H, Tao X, Masters S, Fu H, GOTOH Y, et al. Akt phosphorylation of BAD couples survival signals to the cell-intrinsic death machinery. Cell. 1997;91(2): 231-41.

[105] Dudek H, Datta SR, Franke TF, Birnbaum MJ, Yao R, Cooper GM, et al. Regulation of neuronal survival by the serine-threonine protein kinase Akt. Science. 1997;275(5300): $661-5$.

[106] Ye P, Carson J, D'Ercole AJ. In vivo actions of insulin-like growth factor-I (IGF-I) on brain myelination: studies of IGF-I and IGF binding protein-1 (IGFBP-1) transgenic mice. J. Neurosci. 1995;15(11):7344-56.

[107] Goddard DR, Berry M, Butt AM. In vivo actions of fibroblast growth factor-2 and insulin-like growth factor-I on oligodendrocyte development and myelination in the central nervous system. J. Neurosci. Res. 1999;57(1):74-85.

[108] Luzi P, Zaka M, Rao HZ, Curtis M, Rafi MA, Wenger DA. Generation of transgenic mice expressing insulin-like growth factor-1 under the control of the myelin basic protein promoter: increased myelination and potential for studies on the effects of increased IGF-1 on experimentally and genetically induced demyelination. Neurochem. Res. 2004;29(5):881-9.

[109] Ye P, Li L, Richards RG, DiAugustine RP, D'Ercole AJ. Myelination is altered in insulin-like growth factor-I null mutant mice. Journal of Neuroscience. 2002;22(14):604151.

[110] Zeger M, Popken G, Zhang J, Xuan S, Lu QR, Schwab MH, et al. Insulin-like growth factor type 1 receptor signaling in the cells of oligodendrocyte lineage is required for normal in vivo oligodendrocyte development and myelination. Glia. 2007;55(4):40011.

[111] Freude S, Leeser U, Müller M, Hettich MM, Udelhoven M, Schilbach K, et al. IRS-2 branch of IGF-1 receptor signaling is essential for appropriate timing of myelination. J Neurochem. 2008;107(4):907-17. 
[112] Cui Q-L, Almazan G. IGF-I-induced oligodendrocyte progenitor proliferation requires PI3K/Akt, MEK/ERK, and Src-like tyrosine kinases. J Neurochem. 2007;100(6): 1480-93.

[113] Bibollet-Bahena O, Almazan G. IGF-1-stimulated protein synthesis in oligodendrocyte progenitors requires PI3K/mTOR/Akt and MEK/ERK pathways. J Neurochem. 2009;109(5):1440-51.

[114] Choi K-C, Yoo D-S, Cho K-S, Huh P-W, Kim D-S, Park C-K. Effect of Single Growth Factor and Growth Factor Combinations on Differentiation of Neural Stem Cells. J Korean Neurosurg Soc. 2008;44(6):375.

[115] Konagaya S, Kato K, Nakaji-Hirabayashi T, Arima Y, Iwata H. Array-based functional screening of growth factors toward optimizing neural stem cell microenvironments. Biomaterials. 2011;32(22):5015-22.

[116] Yamada M, Tanabe K, Wada K, Shimoke K, Ishikawa Y, Ikeuchi T, et al. Differences in survival-promoting effects and intracellular signaling properties of BDNF and IGF-1 in cultured cerebral cortical neurons. J Neurochem. 2001;78(5):940-51.

[117] Johnson-Farley NN, Travkina T, Cowen DS. Cumulative activation of akt and consequent inhibition of glycogen synthase kinase-3 by brain-derived neurotrophic factor and insulin-like growth factor-1 in cultured hippocampal neurons. J. Pharmacol. Exp. Ther. 2006;316(3):1062-9.

[118] Ye P, Hu Q, Liu H, Yan Y, D'Ercole AJ. beta-catenin mediates insulin-like growth factor-I actions to promote cyclin D1 mRNA expression, cell proliferation and survival in oligodendroglial cultures. Glia. 2010;58(9):1031-41.

[119] Hu Q, Lee SY, O'Kusky JR, Ye P. Signaling Through the Type 1 Insulin-Like Growth Factor Receptor (IGF1R) Interacts with Canonical Wnt Signaling to Promote Neural Proliferation in Developing Brain. ASN Neuro. 2012.

[120] Danielpour D, Song K. Cross-talk between IGF-I and TGF- $\beta$ signaling pathways. Cytokine \& Growth Factor Reviews. 2006;17(1-2):59-74.

[121] Vogel T, Ahrens S, Buttner N, Krieglstein K. Transforming Growth Factor Promotes Neuronal Cell Fate of Mouse Cortical and Hippocampal Progenitors In Vitro and In Vivo: Identification of Nedd9 as an Essential Signaling Component. Cereb. Cortex. 2010;20(3):661-71.

[122] Sonntag K-C, Simantov R, Björklund L, Cooper O, Pruszak J, Kowalke F, et al. Context-dependent neuronal differentiation and germ layer induction of Smad4-/- and Cripto-/- embryonic stem cells. Mol. Cell. Neurosci. 2005;28(3):417-29.

[123] Li W, Sun W, Zhang Y, Wei W, Ambasudhan R, Xia P, et al. Rapid induction and long-term self-renewal of primitive neural precursors from human embryonic stem cells by small molecule inhibitors. Proc. Natl. Acad. Sci. U.S.A. 2011;108(20):8299304. 
[124] Seoane J, Le H-V, Shen L, Anderson SA, MassaguE J. Integration of Smad and forkhead pathways in the control of neuroepithelial and glioblastoma cell proliferation. Cell. 2004;117(2):211-23.

[125] Parathath SR, Mainwaring LA, Fernandez-L A, Campbell DO, Kenney AM. Insulin receptor substrate 1 is an effector of sonic hedgehog mitogenic signaling in cerebellar neural precursors. Development. 2008;135(19):3291-300.

[126] Kenney AM, Widlund HR, Rowitch DH. Hedgehog and PI-3 kinase signaling converge on Nmyc1 to promote cell cycle progression in cerebellar neuronal precursors. Development. 2004;131(1):217-28. 
